\title{
Dual delivery of nucleic acids and PEGylated-bisphosphonates via calcium phosphate nanoparticles
}

\author{
Sofia Bisso ${ }^{\mathrm{a}}$, Simona Mura ${ }^{\mathrm{b}}$, Bastien Castagner ${ }^{\mathrm{c}}$, Patrick Couvreur ${ }^{\mathrm{b}}$, and Jean- \\ Christophe Leroux ${ }^{\mathrm{a}^{*}}$
}

${ }^{a}$ Institute of Pharmaceutical Sciences, Department of Chemistry and Applied Biosciences, ETH Zurich, Zurich, Switzerland.

${ }^{b}$ Institut Galien Paris-Sud, UMR 8612, CNRS, Université Paris-Sud, Université Paris-Saclay, Faculté de Pharmacie, 5 rue Jean-Baptiste Clément, F-92296 Châtenay-Malabry cedex, France.

${ }^{c}$ Department of Pharmacology and Therapeutics, McGill University, Montréal, Québec, Canada.

*Corresponding author: Prof. J.-C. Leroux

Institute of Pharmaceutical Sciences, ETH Zurich, Vladimir-Prelog-Weg 3, 8093 Zurich, Switzerland.

E-mail: jleroux@ethz.ch

\begin{abstract}
Despite many years of research and a few success stories with gene therapeutics, efficient and safe DNA delivery remains a major bottleneck for the clinical translation of genebased therapies. Gene transfection with calcium phosphate $(\mathrm{CaP})$ nanoparticles brings the advantages of low toxicity, high DNA entrapment efficiency and good endosomal escape properties. The macroscale aggregation of $\mathrm{CaP}$ nanoparticles can be easily prevented through surface coating with bisphosphonate conjugates. Bisphosphonates, such as alendronate, recently showed promising anticancer effects. However, their poor cellular permeability and preferential bone accumulation hamper their full application in chemotherapy. Here, we investigated the dual delivery of plasmid DNA and alendronate using $\mathrm{CaP}$ nanoparticles, with the goal to facilitate cellular internalization of both
\end{abstract}


compounds and potentially achieve a combined pharmacological effect on the same or different cell lines. A pH-sensitive poly(ethylene glycol)-alendronate conjugate was synthetized and used to formulate stable plasmid DNA-loaded CaP nanoparticles. These particles displayed good transfection efficiency in cancer cells and a strong cytotoxic effect on macrophages. The in vivo transfection efficiency, however, remained low, calling for an improvement of the system, possibly with respect to the extent of particle uptake and their physical stability.

\section{Keywords}

Nanoparticles, transfection, calcium phosphate, gene delivery, bisphosphonates, $\mathrm{pH}$-sensitive

\section{Introduction}

Gene therapy represents a promising therapeutic modality for the treatment of inherited genetic disorders and other severe acquired diseases, such as cancer [1]. Despite their huge therapeutic potential, the clinical translation of nucleic acids is in part hampered by their high molecular weight, their polyionic nature and the susceptibility to degradation by nucleases, which restrict their biodistribution and permeability across cell membranes [2]. To overcome the hurdles associated to gene delivery, extensive research efforts have been put in the development of particle-based non-viral carriers, owing to their ability to shield DNA molecules from degradation and facilitate cellular uptake $[3,4]$. The ideal nanosized vehicle should selectively and efficiently deliver a gene to target cells with minimal toxicity. Additional desirable properties are ease of production, long shelf-life, high payload for genetic material and versatility of surface functionalization [4-7]. The most investigated and successful physicochemical methods for DNA delivery involve its electrostatic complexation to polycations (polyplexes) and/or cationic lipids (lipoplexes) [8]. However, these systems often display toxicity issues (necessitating premedication) and, unless sterically stabilized, they 
aggregate in physiological fluids leading to inefficient gene delivery at target sites [9]. Nonionic particulate vehicles, based on lipids $[10,11]$, biodegradable polymers $[3,12]$ or inorganic nanoparticles (NPs) [3,5,13] have been described as alternative strategies to potentially improve gene delivery, safety and efficiency. Among them, calcium phosphate $(\mathrm{CaP})$ NPs are wellestablished for the in vitro delivery of genetic material $[14,15]$. CaP-mediated transfection is based on the electrostatic entrapment of nucleic acid molecules in a relatively non-toxic and dissolvable particulate system, which eventually enhances the endocytosis and endosomal escape of the gene [16]. Nevertheless, rapid aggregation of CaP NPs upon preparation has always represented a significant hurdle for subsequent in vivo applications. Different methods have been investigated to prevent particle growth and agglomeration, mostly involving surface electrostatic stabilization with PEGylated polyanions [17], lipids [18], DNA/siRNA [19] and bisphosphonates (BPs) [16,20,21]. Nitrogen-containing BPs, such as alendronate (Ale), possess high affinity for calcium-containing matrices, and are conventionally used for the treatment of bone-related diseases [22,23]. Recently, BPs have attracted much attention for their direct and indirect anticancer benefits exerted on several non-skeletal tumours, such as breast and prostate cancer [24,25]. Among their multiple effects on the tumour microenvironment (i.e. on tumour associated macrophages), BPs can suppress cell proliferation via induction of apoptosis, primarily through the blockade of the mevalonate pathway [25,26]. Their action is mainly due to inhibition of the enzyme farnesyl pyrophosphate synthase (FPPS), which results in decreased prenylation of small guanosine triphosphate (GTP)-binding proteins (GTPases), ultimately leading to dysregulation of cell-signalling pathways [26,27]. However, the use of BPs as anticancer drugs still encounters limitations related to their rapid distribution to bones and poor membrane permeability. The dual-delivery of Ale and nucleic acids via a particulate system represents a potential strategy to increase the intracellular concentration of both therapeutic agents at target sites. Furthermore, by addressing two different intracellular pathways, the system may elicit a combined effect on therapeutic targets (e.g. cancer cells and/or tumour 
associated macrophages). For this purpose, a carrier with high adsorptive capacity for functional charged molecules must be designed. We previously reported that nucleic acid-loaded CaP NPs coated with a non-cleavable polyethylene glycol (PEG)-Ale derivative induced a modest increase in the intracellular levels of two toxic metabolites, isopentanylpyrophosphate (IPP) and triphosphoric acid 1-adenosin-5'-yl ester 3-(3-methylbut-3-enyl) ester (ApppI) [20]. Accumulation of these molecules is a consequence of inhibition of FFPS, and the effect was attributed to a putative partial enzymatic cleavage of PEG-Ale. Hence, we hypothesized that conjugation of Ale to PEG through an acid-cleavable linker could allow for a more quantitative release of the $\mathrm{BP}$ inside the cell upon endosomal acidification, thus potentially triggering cell death. In this work, we report a CaP-based nanoparticulate carrier for the delivery of both a BP drug and plasmid DNA to cells. A pH-sensitive PEG-Ale chelator was developed to stabilize the NPs, and Ale was conjugated to PEG via a maleic anhydride linker, which is hydrolyzed in mildly acidic conditions. The cellular uptake and transfection efficiency of CaP NPs were evaluated in vitro, and their ability to interfere with the mevalonate pathway was investigated both in macrophages and cancer cells. Finally, the in vivo transfection efficacy of CaP NPs was tested in mice harbouring orthotopic mammary tumours after local administration.

\section{Materials and Methods}

\subsection{Materials}

Ale sodium trihydrate and tris[(1-benzyl-1H-1,2,3-triazol-4-yl)methyl]amine (TBTA) were purchased from Tokyo Chemical Industry Co., Ltd. (Tokyo, Japan). Cobalt thiocyanate was obtained from Siegfried (Zofingen, Switzerland). Triethylamine and 5-hehyn-1-ol 97\% were purchased from Acros Organics (Geel, Belgium). Deuterium oxide $\left(\mathrm{D}_{2} \mathrm{O}\right)$ and deuterated chloroform were obtained from Cambridge Isotope Laboratories (Tewksbury, MA). Methoxy- 
PEG succinimidyl carboxymethyl ester $\left(\mathrm{M}_{\mathrm{n}} \approx 2000 \mathrm{Da}\right)$ was bought from JenKem Technology USA (Plano, TX). Sephadex G-25 PD-10 desalting columns were from GE Healthcare life science (Chalfont St. Giles, UK). 4T1 murine breast cancer cells and J774.2 murine macrophages were purchased from ATCC (Manassas, VA). Dulbecco's modified Eagle medium (DMEM) with GlutaMAX ${ }^{\mathrm{TM}}$ (high glucose), phenol red-free DMEM, Opti-MEMTM I reduced serum medium, fetal bovine serum (FBS), penicillin/streptomycin stock solution (10,000 IU/mL penicillin and 10,000 $\mu \mathrm{g} / \mathrm{mL}$ streptomycin), trypsin $0.25 \%(\mathrm{~m} / \mathrm{v}) / 1 \mathrm{mM}$ EDTA solution, phosphate buffered saline (PBS), Live Cell Imaging Solution for cell culture, Hoechst 33342 and ProLong ${ }^{\text {TM }}$ Diamond antifade mountant were obtained from Life Technologies (ThermoFisher Scientific, Carlsbad, CA). MycoAlert PLUS Mycoplasma Detection Kit was purchased from Lonza (Basel, Switzerland). Label $\mathrm{IT}^{\circledR}$ plasmid delivery control, fluorescein labeled pDNA (2.7 kb), was obtained from LabForce (Muttenz, Switzerland). X-tremeGENE ${ }^{\mathrm{TM}}$ 9 DNA Transfection Reagent was bought from Roche Pharma (Reinach, Switzerland). CellTiter 96 AQueous One Non-Radiactive Cell Proliferation Assay based on 3-(4,5-dimethylthiazol-2yl)-5-(3-carboxymethoxyphenyl)-2-(4-sulfophenyl)-2H-tetrazolium (MTS) was from Promega (Duebendorf, Switzerland). COmplete ${ }^{\mathrm{TM}}$ EDTA-free protease inhibitor cocktail was obtained from Roche Diagnostics (Mannheim, Germany). Immun-Blot ${ }^{\circledR}$ poly(vinylidene difluoride) membranes were purchased from Bio-Rad Laboratories (Hercules, CA). Mouse monoclonal Rap1A (C-10) antibody, mouse monoclonal $\beta$-actin (C4) antibody and ImmunoCruz ${ }^{\circledR}$ Western blotting Luminol Reagent were obtained from Santa Cruz Biotechnology (Dallas, TX). Horseradish peroxidase (HRP)-conjugated goat anti-mouse IgG polyclonal antibody was purchased from Dako (Glostrup, Denmark). Super RX X-ray films were obtained from Fujifilm (Tokyo, Japan). In vivo-jetPEI ${ }^{\circledR}$ was purchased from Polyplus-transfection S.A (Illkirch, France). Roti ${ }^{\circledR}$ Histofix 4\% PFA solution was from Carl Roth (Karlsruhe, Germany) and optimal cutting temperature (OCT) embedding medium was bought from CellPath (Powys, United Kingdom). ATTO488-GFP-Booster was purchased from ChromoTek (Planegg- 
Martinsried, Germany). All other chemicals were obtained from Sigma-Aldrich (Buchs, Switzerland).

\subsection{Synthesis and characterization of PEG-Ale coating agent}

Synthesis of pH-sentitive PEG-2-(pent-1'-yne) maleic acid Ale amide (PEG-ma-Ale), PEG-1methyl-2-(2'-carboxyethyl) maleic acid Ale amide (PEG-mma-Ale) and the pH-stable PEGamide-Ale (PEG-a-Ale) control are described in detail in the supplementary information section (Fig. S1-S10).

\subsection{Determination of Ale release from PEG-Ale prodrugs}

The kinetics of Ale release from the PEG-ma-Ale and PEG-mma-Ale maleic acid amide prodrugs were monitored at room temperature (RT) by ${ }^{1} \mathrm{H}-\mathrm{NMR}$ spectroscopy at different $\mathrm{pH}$ values. Each derivative was dissolved at a $20 \mathrm{mg} / \mathrm{mL}$ concentration in $\mathrm{D}_{2} \mathrm{O}$-based $20 \mathrm{mM}$ $\mathrm{Na}_{2} \mathrm{HPO}_{3}$ buffer, and the $\mathrm{pH}$ of the solution was adjusted to 7.4 or 5.0 with $1 \mathrm{~N} \mathrm{NaOD}$ or $1 \mathrm{~N}$ DCl. For the measurement at basic $\mathrm{pH}$ values, a $20-\mathrm{mM} \mathrm{Na}_{2} \mathrm{CO}_{3}$ buffer was used, and the $\mathrm{pH}$ was adjusted to 9.0 by addition of $1 \mathrm{~N} \mathrm{NaOD}$ or $1 \mathrm{~N} \mathrm{DCl}$. For the hydrolysis experiments on PEG-ma-Ale performed at $\mathrm{pH}$ 5.0, an aliquot of the prodrug was incubated in acidic buffer for each time point, followed by purification via size-exclusion chromatography using a Sephadex G-25 PD-10 column (eluent $20 \mathrm{mM} \mathrm{Na}_{2} \mathrm{HPO}_{3}$ buffer, $\mathrm{pH}$ 8.5). The purified PEG-ma-Ale derivative was lyophilized and subsequently resuspended at a $20 \mathrm{mg} / \mathrm{mL}$ concentration in $\mathrm{D}_{2} \mathrm{O}$ based $20 \mathrm{mM} \mathrm{Na} \mathrm{HPO}_{3}, \mathrm{pH} 7.4$ for NMR analysis of hydrolysis. For each time point, semiquantitative degradation analysis on PEG-ma-Ale was calculated according to Eq. (1):

Hydrolysis $(\%)=[1-($ integration of peak at $3.24 \mathrm{ppm} / \mathrm{PRE})] \cdot 100$ Eq. (1) 
where PRE is the value of integration of peak at $3.24 \mathrm{ppm}$ at time $10 \mathrm{~min}$ of PEG-maAle dissolved in $\mathrm{D}_{2} \mathrm{O}$-based $20 \mathrm{mM} \mathrm{Na} \mathrm{HPO}_{3}$ buffer, $\mathrm{pH} 7.4$ (Fig. S11). For comparison purposes between NMR spectra, integration of the peak at $2.6 \mathrm{ppm}$ was normalized to $2 \mathrm{H}$ for each time point.

In the same way, the extent of hydrolysis of PEG-mma-Ale was calculated according to Eq. (2):

$$
\text { Hydrolysis }(\%)=[1-(\text { integration of peak at } 3.21 \mathrm{ppm} / \mathrm{PRE})] \cdot 100
$$

where PRE is the value of integration of peak at $3.21 \mathrm{ppm}$ at time $10 \mathrm{~min}$ of PEG-mmaAle dissolved in $\mathrm{D}_{2} \mathrm{O}$-based $20 \mathrm{mM} \mathrm{Na} \mathrm{CO}_{3}$ buffer, $\mathrm{pH} 10$ (Fig. S14). To compare NMR spectra, integration of the peak at $4.29 \mathrm{ppm}$ was normalized to $2 \mathrm{H}$ for each time point.

\subsection{Plasmid DNA amplification}

Plasmid DNA (pc3DNA; enhanced green fluorescent protein (EGFP) insert, ampicillin resistance) from Addgene (Cambridge, MA) was amplified in DH5 $\alpha$ E. coli and then extracted and purified using a plasmid purification maxi kit (Qiagen, Valencia, CA). Purity was assessed by the ratio of absorbance at 260 and $280 \mathrm{~nm}$, using a NanoPhotometer spectrophotometer (Implen, München, Germany). Plasmids with an absorbance ratio of $\sim 1.8$ were considered as pure.

\subsection{Particle preparation}

CaP NPs were prepared according to reference [21]. Briefly, one volume of $50 \mathrm{mM}$ HEPES buffer (containing $140 \mathrm{mM} \mathrm{NaCl}$ and $1.5 \mathrm{mM} \mathrm{Na}_{2} \mathrm{HPO}_{3}, \mathrm{pH}$ 7.4) was mixed with one volume of a $250-\mathrm{mM} \mathrm{CaCl} 2$ solution containing $20 \mu \mathrm{g} / \mathrm{mL}$ pEGFP, under vigorous agitation. After 
particles nucleation, one volume of 10 or $20 \mu \mathrm{M}$ PEGylated chelator in $10 \mathrm{mM}$ TRIS, pH 7.4, was quickly added to stabilize the particles. For cytotoxicity assays, additional solutions with 40, 50 and $80 \mu \mathrm{M}$ of PEGylated chelators were used. CaP NPs for in vivo studies were prepared according to the standard method using buffers with a lower ionic strength (vide infra) to limit the increase in osmolality after particles concentration [28]. One volume of $7 \mathrm{mM}$ HEPES buffer (containing $18 \mathrm{mM} \mathrm{NaCl}$ and $1.5 \mathrm{mM} \mathrm{Na}_{2} \mathrm{HPO}_{3}, \mathrm{pH}$ 7.4) was mixed with one volume of $125 \mathrm{mM} \mathrm{CaCl} 2$ (containing $40 \mu \mathrm{g} / \mathrm{mL}$ pEGFP), followed by quick addition of one volume of $15 \mu$ M PEG-ma-Ale in 2 mM TRIS, pH 7.4. Subsequently, $375 \mu$ L of NP suspension was mixed 1:1 $(v / v)$ with a $26 \mathrm{mg} / \mathrm{mL}$ trehalose solution in ultrapure water, snap-frozen in liquid nitrogen and lyophilized. For the in vivo experiments, the freeze-dried CaP NPs were reconstituted in ultrapure water to a final volume of $50 \mu \mathrm{L}$, vortexed shortly and sonicated for $5 \mathrm{~min}$.

\subsection{Particle characterization}

Particle size, polydispersity index (PDI) and $\zeta$-potential were determined by dynamic light scattering (DLS) and laser Doppler anemometry respectively, using a DelsaNano C Particle Analyzer (Beckman Coulter, Krefeld, Germany). The CONTIN method was used to calculate the hydrodynamic diameter of the particles. $\zeta$-potential was measured after dilution of the particles 1:2 $(v / v)$ in $10 \mathrm{mM}$ TRIS, $\mathrm{pH}$ 7.4. Osmolality was measured with a freezing point osmometer (Osmomat 3000, Gonotec GmbH, Berlin, Germany). Transmission electron microscopy (TEM) of the particle suspension was performed at $100 \mathrm{kV}$ (FEI Morgagni268, FEI Company, Hillsboro, OR). To calculate the encapsulation efficiency, Label IT $^{\circledR}$ plasmid fluorescein delivery control was loaded on CaP NPs $(225 \mu \mathrm{L}$, final pDNA concentration of 6.66 $\mu \mathrm{g} / \mathrm{mL})$. The particles were then isolated by centrifugation $\left(30 \mathrm{~min}, 4{ }^{\circ} \mathrm{C}, 18,000 x \mathrm{~g}\right)$ and 180 $\mu \mathrm{L}$ of supernatant were taken to measure the fluorescence intensity of free pDNA $\left(\lambda_{\mathrm{ex}}=485\right.$ $\mathrm{nm}, \lambda_{\mathrm{em}}=520 \mathrm{~nm}$ ) with a plate reader (Infinite M-200, Tecan, Männedorf, Switzerland). 
Encapsulation efficiency (EE) was estimated by subtracting the free DNA concentration in the supernatant from the total concentration, using the fluorescence signals (FI), according to Eq. (3):

$$
\mathrm{EE}(\%)=\frac{\text { FI total pDNA added }- \text { FI pDNA in supernatant }}{\text { FI total pDNA added }} \cdot 100
$$

\subsection{Colloidal stability of CaP NPs}

Stability of $10 \mu \mathrm{M}$ PEG-ma-Ale-coated CaP NPs at different pHs was evaluated over time by DLS after adjusting the $\mathrm{pH}$ to $7.0,6.8$ or 6.5 by addition of $1 \mathrm{~N} \mathrm{NaOH}$ or $1 \mathrm{~N} \mathrm{HCl}$. The stability in serum-containing media of pEGFP loaded NPs (pDNA concentration: $6.66 \mu \mathrm{g} / \mathrm{mL}$ ) prepared with 10 and $20 \mu \mathrm{M}$ feeding amount of PEG-ma-ALE was assessed overtime at $37{ }^{\circ} \mathrm{C}$ in complete medium containing FBS. CaP NPs were diluted 1:7 $(v / v)$ in DMEM containing 10 or $50 \%$ FBS, and their hydrodynamic diameter was recorded over time by DLS at $37{ }^{\circ} \mathrm{C}$. Additionally, the stability of pEGFP-loaded CaP NPs coated with different PEG-ma-Ale feeding amounts $(10,15$ and $20 \mu \mathrm{M})$ was measured by DLS at RT at defined time intervals, for up to 21 days.

\subsection{Cell culture}

4T1 (murine mammary carcinoma) and J774.2 (murine macrophage-like) cells were grown in DMEM with GlutaMAX ${ }^{\mathrm{TM}}$ (high glucose) supplemented with $10 \%(v / v)$ FBS, $100 \mathrm{IU} / \mathrm{mL}$ penicillin and $100 \mu \mathrm{g} / \mathrm{mL}$ streptomycin. Cells were kept at $37{ }^{\circ} \mathrm{C}$ in a humidified atmosphere containing 5\% $\mathrm{CO}_{2}$. Cells were used from passages 3 to 20 , and regularly checked for mycoplasma contamination. 


\subsection{In vitro particles uptake}

The uptake of pDNA loaded CaP NPs stabilized with PEG-ma-Ale was evaluated in 4T1 and J774.2 cells. In order to track the internalized particles, CaP NPs were loaded with Label IT $^{\circledR}$ Fluorescein Plasmid Delivery Control as model pDNA. 4T1 and J774.2 cells were seeded into 24-well tissue-treated plates at a density of 60,000 and 100,000 cells/well, respectively, in 0.5 $\mathrm{mL}$ complete DMEM containing $10 \%$ FBS. After $24 \mathrm{~h}$ incubation at $37{ }^{\circ} \mathrm{C}$ in a humidified atmosphere containing $5 \% \mathrm{CO}_{2}$, the medium was changed to complete DMEM supplemented with $10 \%$ FBS, and particles prepared with 10 or $20 \mu \mathrm{M}$ feeding amounts of PEG-ma-ALE were diluted 1:6.66 $(v / v)$ in complete medium to a final pDNA concentration of $1 \mu \mathrm{g} / \mathrm{mL}$. After $5 \mathrm{~h}$ or $24 \mathrm{~h}$ incubation, the medium was removed, and cells were washed twice with $200 \mu \mathrm{L}$ PBS. Then, 4T1 cells were detached by trypsinization, followed by addition of complete medium to stop the trypsin action. To detach $\mathrm{J} 774.2$ cells, $0.5 \mathrm{~mL}$ of complete medium were added to each well, and cells were recovered with a cell scraper. Cells were isolated by centrifugation $\left(10 \mathrm{~min}, 4{ }^{\circ} \mathrm{C}, 300 \times \mathrm{g}\right.$ ) and subsequently resuspended in ice cold FACS buffer (PBS, $2 \mathrm{mM}$ EDTA, $0.5 \% \mathrm{~m} / \mathrm{v}$ BSA). Data for 10,000 cells were collected on a CytoFLEX Flow Cytometer (Beckman Coulter Inc., Brea, CA) and analyzed using the FlowJo software (Tree Star Inc., Ashland, OR). Uptake of CaP NPs was determined as percentage of FITCpositive cells, compared to control wells that did not receive CaP NPs. For the uptake in the inverted configuration, 4T1 and J774.2 cells were seeded on 13-mm Nunc ${ }^{\mathrm{TM}}$ Thermanox $^{\mathrm{TM}}$ Coverslips (ThermoFisher Scientific, Carlsbad, CA) in a 24-well plate at a density of 60,000 and 100,000 cells/well respectively. After $24 \mathrm{~h}$ incubation at $37^{\circ} \mathrm{C}$ in a humidified atmosphere containing $5 \% \mathrm{CO}_{2}, 0.5 \mathrm{~mL}$ of complete medium containing $10 \% \mathrm{FBS}$ were added to each well of a 24-well plate, and CaP NPs containing fluorescein-labeled pDNA were added at a 1:6.66 $(v / v)$ final dilution, corresponding to a final pDNA concentration of $1 \mu \mathrm{g} / \mathrm{mL}$. The coverslips on which cells adhered were carefully transferred upside down onto the surface of the medium. 
After $24 \mathrm{~h}$, the medium was removed and the coverslips were transferred in a 24-well plate and washed twice with PBS. Cells were prepared for FACS analysis and data were processed as previously described for the uptake in upright configuration.

\subsection{In vitro particles transfection efficiency}

4T1 and J774.2 cells were seeded into 24-well tissue-treated plates at a density of 20,000 and 80,000 cells/well, respectively, in $0.5 \mathrm{~mL}$ complete DMEM containing 10\% FBS. After $24 \mathrm{~h}$ incubation at $37{ }^{\circ} \mathrm{C}$ in humidified atmosphere containing $5 \% \mathrm{CO}_{2}$, the medium was removed and the cells were incubated with CaP NPs formulations diluted 1:6.66 $(v / v)$ in Opti-MEM containing $10 \%$ FBS, to a final pDNA concentration of $1 \mu \mathrm{g} / \mathrm{mL}$. Cells were exposed to PEGma-Ale stabilized CaP NPs for different incubation times (5, 24 or 48 h). X-tremeGENETM was used as positive control, as well as not stabilized CaP NPs. After the 5 and $24 \mathrm{~h}$ incubation time points, the medium containing the CaP NPs was removed, the cell layer was washed twice with PBS and then incubated with $500 \mu \mathrm{L}$ complete medium for up to $48 \mathrm{~h}$ after particles addition. Then, the medium was aspirated and the cell layer was washed twice with PBS. Cells were prepared for FACS analysis and data were processed as described in section 2.9. EGFP expression was evaluated as the percentage of FITC-positive cells, compared to control wells not exposed to CaP NPs. Fluorescence images of EGFP expressing cells were acquired with a LEICA DMI600B epifluorescence microscope (Leica Microsystem, Wetzlar, Germany).

\subsection{In vitro particles cytotoxicity}

The viability of 4T1 and J774.2 cells after incubation with CaP NPs stabilized with the different PEG-Ale stabilizing agents was evaluated by the MTS assay. 4T1 and J774.2 cells were seeded into flat-bottomed 96-well plates at a density of 5000 and 10,000 cells/well, respectively, in 100 $\mu \mathrm{L}$ complete DMEM containing 10\% FBS. After $24 \mathrm{~h}$ incubation, the medium was removed 
and the cells were incubated with different formulations of CaP NPs diluted 1:6.66 $(v / v)$ in complete medium, to achieve different final concentrations of each PEG-ma-Ale or PEG-a-Ale stabilizing agent $(0.5,1,2,4$, and $5 \mu \mathrm{M}$, calculated based on the corresponding Ale molar concentrations). Cells were exposed to the CaP NPs for different incubation times (5, 24 or 48 h). As control, cells were incubated with only PEG-ma-Ale. After the 5 and $24 \mathrm{~h}$ incubation time points, the medium containing the CaP NPs was removed, the cell layer was washed twice with PBS, and $100 \mu \mathrm{L}$ of complete medium were added to each well for up to $48 \mathrm{~h}$ from particles addition. Then, the medium was aspirated, the cell layer was washed twice with PBS and 120 $\mu \mathrm{L}$ of DMEM without phenol red containing the MTS reagent in the ratio 6:1 $(v / v)$ were added. After $1 \mathrm{~h}$ incubation at $37^{\circ} \mathrm{C}$, the absorbance of the wells was measured at $490 \mathrm{~nm}$ with a Tecan plate reader. Cell viability was determined according to Eq. (4):

$$
\text { Cell viability }(\%)=\left(\mathrm{OD}_{490} \text { sample } / \mathrm{OD}_{490} \text { control }\right) \cdot 100
$$

where $\mathrm{OD}_{490}$ sample represents the optical density (OD) of the wells treated with CaP NPs, and $\mathrm{OD}_{490}$ control represents the wells treated with growth medium only. One mM hydrogen peroxide was used as positive toxic control (viability $<20 \%$ ), and wells containing only reaction mixture but no cells were used as blank.

\subsection{Western Blot analysis of Rap1A}

4T1 and J774.2 cells were seeded in 12-well plates at 40,000 and 80,000 cells/well, respectively, in $1 \mathrm{~mL}$ complete DMEM containing 10\% FBS. Twenty-four hours after seeding, CaP NPs stabilized with PEG-ma-Ale or PEG-a-Ale were added to each well at a 1:6.66 $(v / v)$ final dilution, corresponding to different PEG-Ale concentrations $(0.5,2$ and $4 \mu \mathrm{M}$, calculated based on the corresponding Ale concentrations). Complete medium without NPs was used as negative control. After $24 \mathrm{~h}$ incubation, the medium was removed, cells were washed twice 
with PBS and cell lysates were prepared in $120 \mu \mathrm{L}$ lysis buffer $(20 \mathrm{mM}$ Tris- $\mathrm{HCl} \mathrm{pH} 7.7$, $150 \mathrm{mM} \mathrm{NaCl}, 5 \mathrm{mM}$ EDTA, $1 \%$ v/v Triton X-100, $25 \mathrm{mM} \mathrm{NaF}, 1 \mathrm{mM}$ phenylmethylsulfonyl fluoride, $1 \mathrm{mM}$ sodium orthovanadate), supplemented with cOmplete ${ }^{\mathrm{TM}}$ EDTA-free protease inhibitor cocktail, on ice for $15 \mathrm{~min}$. Cell debris were removed by centrifugation $\left(15 \mathrm{~min}, 4{ }^{\circ} \mathrm{C}\right.$, $15,000 \times g$ ) and protein concentration in the supernatants was determined using the BCA assay (ThermoFisher Scientific, Waltham, MA). Ten micrograms of total protein per sample were resolved by a $12 \%$ SDS-PAGE and transferred to a PVDF membrane. The membrane was blocked with Tris-buffered saline containing $0.1 \%(\mathrm{v} / \mathrm{v})$ polysorbate 20 and $5 \%(\mathrm{~m} / \mathrm{v})$ skim milk (blocking buffer) for $1 \mathrm{~h}$ at RT. The membrane was cut in two at $35 \mathrm{kDa}$, determined by molecular weight markers. The lower part containing Rap1A (22 kDa) was incubated overnight at $4{ }^{\circ} \mathrm{C}$ with mouse Rap1A monoclonal antibody diluted 1:500 in blocking buffer. The upper part containing $\beta$-actin (internal control) was incubated with mouse polyclonal anti- $\beta$-actin antibody at a dilution of 1:500 in blocking buffer. Membranes were washed with Tris-buffered saline containing $0.1 \%(v / v)$ polysorbate 20 , and then incubated for $2 \mathrm{~h}$ with the secondary antibody, horseradish peroxidase-conjugated polyclonal goat anti-mouse $\operatorname{IgG}$, diluted 1:1000 in blocking buffer. Membranes were washed with Tris-buffered saline containing $0.1 \%(v / v)$ polysorbate 20 and protein bands were detected with ImmunoCruz ${ }^{\circledR}$ Western blotting Luminol Reagent and revealed on Super RX X-ray films, using an AGFA Curix 60 film processor (AGFA, Mortsel, Belgium).

\subsection{In vivo transfection efficiency study}

All animal experiments were approved by the Animal Care Committee of the University ParisSud (registered under no. 11894/2017102312072785). Experimental procedures were performed according to the 2010/63/EU European directive and the instructions of laboratory animal care and legislation in force in France. Female BALB/c mice (6-8 weeks) were 
purchased from Janvier Labs (Le Genest-Saint-Isle, France). To establish the orthotopic mammary tumours, 4T1 cells were harvested using trypsin, isolated by centrifugation at $200 \mathrm{x}$ $g \times 5$ min and resuspended in PBS at a density of $1 \times 10^{6}$ cells $/ \mathrm{mL}$. Mice were anesthetized under isoflurane $(3 \% v / v$ in $1 \mathrm{~mL} / \mathrm{min}$ oxygen flow) and $50 \mu \mathrm{L}$ of the cell suspension were injected in the fourth inguinal mammary fat pad, using a 29-G syringe (Terumo, Tokyo, Japan). Tumour size was regularly measured with a caliper, and its volume was estimated using Eq. (5):

$$
\mathrm{v}=\left(a b^{2}\right) / 2
$$

where $a$ is the larger tumour dimension and $b$ the smallest. When the tumours reached a volume of approximatively $100 \mathrm{~mm}^{3}$, mice were anaesthetized under isoflurane $(3 \% \mathrm{v} / \mathrm{v}$ in 1 $\mathrm{mL} / \mathrm{min}$ oxygen flow) and divided into 4 random groups of 3-8 animals, that received the following treatments: (i) pEGFP loaded CaP NPs, (ii) pEGFP in 5\% $(\mathrm{m} / \mathrm{v})$ glucose, (iii) pEGFP complexed with in vivo-jetPEI ${ }^{\circledR}$ with a N/P ratio of 6 , in $5 \%(\mathrm{~m} / \mathrm{v})$ glucose (positive control), (iv) $5 \%(\mathrm{~m} / \mathrm{v})$ glucose (negative control, $\mathrm{n}=3$ ). The formulations were slowly administered intratumorally in multiple spots, at a final pDNA dose of $2 \mu \mathrm{g}$ in $20 \mu \mathrm{L}$. The mice received a total of three doses of $2 \mu \mathrm{g}$ pDNA each, every other day over one week. After $24 \mathrm{~h}$ from the last dose, mice were anaesthetized under isoflurane $(3 \% \mathrm{v} / \mathrm{v}$ in $1 \mathrm{~mL} / \mathrm{min}$ oxygen flow) and sacrificed via cervical dislocation. Excised tumour tissues were fixed in $4 \%$ PFA at $4{ }^{\circ} \mathrm{C}$ overnight, then washed twice with PBS and placed in $15 \%(\mathrm{~m} / \mathrm{v})$ sucrose in PBS at $4{ }^{\circ} \mathrm{C}$ until sinking. The specimens were then transferred in $30 \%(\mathrm{~m} / \mathrm{v})$ sucrose in PBS and stored at $4{ }^{\circ} \mathrm{C}$ overnight. The samples were embedded in OCT and subsequently frozen on a metal support placed in liquid nitrogen. The frozen samples were stored at $-80{ }^{\circ} \mathrm{C}$ until cryosectioning procedure. Tissue cryosections $(10 \mu \mathrm{m})$ were cut with a CryoStar NX70 (Thermo Fisher Scientific, Waltham, MA) and the slices were mounded on SuperFrost Plus glass slides (Thermo Fisher Scientific, Waltham, MA). The slices were fixed and permeabilized in ice cold 
methanol for $15 \mathrm{~min}$, then blocked in 5\% $(\mathrm{m} / \mathrm{v})$ BSA in PBS for $30 \mathrm{~min}$. ATTO488-GFPBooster was added at a 1:200 dilution in blocking buffer, followed by overnight incubation at $4{ }^{\circ} \mathrm{C}$. The slices were stained for 20 min with Hoechst 33342 added at a 1:2000 dilution in PBS, then mounted on a coverslip using ProLong ${ }^{\mathrm{TM}}$ Diamond and visualized with a Leica epifluorescence microscope.

\subsection{Statistical analysis}

All values were expressed as mean \pm standard deviation. All statistical analyses were performed using the GraphPad Prism software, version 8. Normality was evaluated with the KolmogorovSmirnov test. When data followed normal distribution, pairwise comparison between multiple groups was performed using the one-way analysis of variance (ANOVA) test, followed by Tukey's (Holm-Sidak) post-hoc test. For non-normal distribution (e.g., cell viability assays) treatment groups were compared with one-way Kruskall-Wallis test followed by Dunn's posthoc test. Results were considered statistically significant at $p \leq 0.05$.

\section{Results and Discussion}

\subsection{Synthesis and characterization of the PEGylated chelators}

The PEG-ma-Ale derivative was synthetized by conjugation of Ale to one PEG molecule, using a monosubstituted maleic anhydride as acid-cleavable linker. The cyclic anhydride was synthetized via a three-step procedure from a terminal alkyne bearing a primary alcohol, which was converted to aldehyde, followed by Mannich cyclization and oxidation to cyclic anhydride. Then, a maleic acid amide was obtained by coupling with Ale under basic conditions, and a PEG chain was introduced through a copper(I)-catalysed alkyne-azide cycloaddition reaction, to finally afford PEG-ma-Ale (Fig. 1a). In order to compare the Ale release rate from a different anhydride linker, a disubstituted maleic anhydride linker, i.e. 2-propionic-3-methylmaleic 
anhydride (here named mma), was coupled to one PEG molecule via an ester bond and then conjugated to Ale, to yield PEG-mma-Ale (Fig. 1b). The PEG-a-Ale stable derivative was obtained by conjugation of Ale and PEG via an amide bond, as previously reported (Fig. S10) [20]. The hydrolysis rate of the two $\mathrm{pH}$-sensitive PEG-Ale derivatives at various $\mathrm{pH}$ values was measured over time by ${ }^{1} \mathrm{H}-\mathrm{NMR}$ spectroscopy. A negligible $(<10 \%)$ Ale release was observed after 24 h incubation of PEG-ma-Ale both at pH 9.0 and 7.4 (Fig. 2a and S11). The compound slowly hydrolyzed at pH 5.0 (Fig. S12), with $\sim 50 \%$ Ale released after about 3 h (Fig. 2a). The amide was almost fully cleaved (> 80\% hydrolysis) within $1 \mathrm{~h}$ at $\mathrm{pH} 4.0$ (Fig. 2a). At this $\mathrm{pH}$ value, Ale release was complete after $6 \mathrm{~h}$ incubation, as inferred from the disappearance of the methylene protons next to the nitrogen in the intact amide in the NMR spectrum (at $3.24 \mathrm{ppm}$ ) (Fig S13). Conversely, Ale was quickly released from PEG-mma-Ale at pH 7.4 (Fig. S14), with $\sim 50 \%$ of hydrolysis reached after about 50 min (Fig. 2b), while a slow hydrolysis was observed at $\mathrm{pH} 9.0$, with $50 \%$ of the Ale released within $24 \mathrm{~h}$. In cells, the $\mathrm{pH}$ varies significantly depending on the cellular compartment, ranging from 8 in mitochondria to as low as 5.0 to 4.0 in endosomes and lysosomes. Moreover, the $\mathrm{pH}$ is generally slightly lower in tumour mass $\mathrm{pH}$ $\approx 6.5-7.2$ ) than in blood and normal tissues [29]. The optimal $\mathrm{pH}$ sensitive moiety for intracellular release should be stable in biological fluids and cleavable within the cell, exploiting mild $\mathrm{pH}$ changes. Maleic anhydrides react with amines to yield maleic acid amides, which are cleaved in slightly acidic environments, when the nitrogen of the amide bond is in equilibrium with its protonated form. The whole cleavage process is driven by intramolecular catalysis of the anhydride that favors the formation of the cyclic form (Fig. S15) [30]. This peculiar characteristic of acid labile maleic anhydride derivatives was extensively exploited in a variety of pharmaceutical applications, such as to generate prodrugs for controlled drug release [31], or to design $\mathrm{pH}$-dependent charge-conversion derivatives that confer endosomolytic properties to a carrier [32-34]. Depending on the nature of the substituents at the unsaturated carbon-carbon bond, as well as on the $\mathrm{pK}_{\mathrm{a}}$ of the conjugated amine, the release rate of the 
amine can be finely tuned at acidic $\mathrm{pH}$. For instance, Kang S. et al [35] observed that a faster amine release could be achieved at a higher degree of substitution at the cis-double bond of the anhydride ring, due to the Thorpe-Ingold effect [36,37]. Accordingly, the monosubstituted anhydride linker provided appropriate stability to PEG-ma-Ale at neutral $\mathrm{pH}$, and controlled degradability at weak acidic $\mathrm{pH}$. On the other hand, substitution of the hydrogen atom with a methyl group at the cis-double bond of PEG-mma-Ale accelerated the release rate of the BP at $\mathrm{pH}$ 7.4. Therefore, the conjugate obtained from the disubstituted anhydride was not selected for further studies, due to its predicted instability in formulation buffers and biological fluids.

\subsection{CaP NPs preparation and characterization}

PEG-ma-Ale stabilized CaP NPs were prepared by co-precipitation of calcium and phosphate ions in aqueous buffer, followed by quick addition of the Ale conjugate. Blank particles (not loaded with pDNA) had a hydrodynamic diameter of about $140 \mathrm{~nm}$ and a PDI of 0.1-0.2, while pEGFP encapsulation increased the particle size to around $170 \mathrm{~nm}$ (Table 1). In both cases, $\zeta$ potential values were slightly negative and close to neutrality $(-5$ to $-2 \mathrm{mV})$, which is in agreement with previous data for similar NPs [20]. The size difference between 10 and $20 \mu \mathrm{M}$ PEG-ma-Ale was not significant both for blank and pDNA loaded CaP NPs. To confirm DNA entrapment, the gene loading efficiency was measured, and found to be of $95.4 \pm 0.9 \%$ and 93.7 $\pm 1.0 \%$ at a PEG-ma-Ale concentration of 10 and $20 \mu \mathrm{M}$, respectively. Morphology of CaP NPs was investigated by TEM. CaP NPs displayed a spherical shape with a diameter of ca. $50 \mathrm{~nm}$, forming clusters of several single units, with a smaller size compared to the hydrodynamic diameter measured via DLS (Fig. 3a). This finding correlates with previously reported data of similar systems [21], indicating that the CaP NPs may be present in suspension as small aggregates of single particles. No diffraction spots typical of crystalline materials were observed in the selected-area electron diffraction (SAED) (Fig. 3b), revealing that the particles 
were mainly composed of amorphous calcium phosphate [21]. Size, morphology and crystallinity degree of $\mathrm{CaP}$ nanoprecipitates are affected by the reaction conditions, such as initial $\mathrm{Ca} / \mathrm{P}$ ratio, $\mathrm{pH}$, presence of additives (e.g. ions, charged molecules and polymers), temperature and pressure $[38,39]$. When CaP NPs are produced by precipitation under super saturated conditions, amorphous $\mathrm{CaP}$ is generally formed first during the nucleation process, being the most kinetically favored CaP form [21,40,41]. For the in vivo studies (vide infra), the NPs suspension had to be concentrated to allow a sufficient dose of pDNA to be delivered. The particles could not be concentrated by centrifugation or ultrafiltration as aggregation and partial dissolution were observed. Therefore, the NPs were freeze-dried in the presence of a trehalose as a lyoprotectant. HEPES and TRIS buffers at lower ionic strength were used, to compensate for the increase in osmolality that occurred after concentration. pEGFP loaded CaP NPs prepared under "low osmolality" conditions had a hydrodynamic diameter of about $150 \mathrm{~nm}$ with a PDI of 0.15 (Fig. S16) and an osmolality of $139 \mathrm{mOsm} / \mathrm{kg}$. Resuspension of the particles after lyophilisation resulted in a small but significant $(\mathrm{p}=0.0480)$ increase in size to $\sim 200 \mathrm{~nm}$. CaP NPs prepared with $10 \mu \mathrm{M}$ PEG-ma-Ale were stable at RT for 3 days, whereas 15 and 20 $\mu$ M PEG-ma-Ale increased particle stability to 7 and 15 days, respectively (Fig S17). While a higher concentration of PEGylated chelator was shown to be more efficient in preventing particle size growth [20], slow PEG-ma-Ale hydrolysis on the particle surface could explain the physical instability of the system upon long term storage. CaP NP stability in the presence of serum components was assessed by DLS at $37{ }^{\circ} \mathrm{C}$. The average hydrodynamic diameter of PEG-ma-Ale stabilized CaP NPs did not significantly vary after $6 \mathrm{~h}$ incubation in DMEM containing 10 or $50 \%$ FBS, indicating good colloidal stability in biological media (Fig. 4a), at least under these non-diluted conditions. The addition of $10 \%$ FBS, resulted in a size increase from $\sim 160$ to $\sim 220-240 \mathrm{~nm}$, which was more pronounced at a lower PEG-ma-Ale feeding concentration $(10 \mu \mathrm{M})$. This effect may be related to unspecific protein binding on the particle surface and/or more pronounced particle aggregation [21]. To assess the $\mathrm{pH}$-dependent 
dissolution of the particles, PEG-ma-Ale stabilized CaP NPs were incubated at RT in $10 \mathrm{mM}$ TRIS, and $\mathrm{pH}$ was slowly decreased by addition of $1 \mathrm{~N} \mathrm{HCl}$. No significant change in size was initially observed in the $\mathrm{pH}$ range 6.8-7.4 (Fig. 4b). Upon acidification of the suspension buffer from $\mathrm{pH} 7.4$ to $\mathrm{pH}$ 6.5, mimicking the early endosome environment, size of the particles dropped to $\sim 5 \mathrm{~nm}$, indicating nearly complete dissolution.

\subsection{Uptake of CaP NPs in 4T1 and J774.2 cells}

To investigate the uptake of PEG-ma-Ale coated CaP NPs in 4T1 cancer cells and J774.2 macrophages, the particles were loaded with a fluorescein-labeled pDNA and incubated with the cells for 5 or $24 \mathrm{~h}$ in complete medium containing 10\% FBS. X-tremeGENETM, a commercially available lipid-based transfection reagent, was used as positive control. Although the extent of cell-associated fluorescence was slightly different between the two cell lines, in both cases a modest uptake ( $20 \%)$ was observed after $5 \mathrm{~h}$ incubation compared to the positive control $(\sim 70 \%)$. A small but significant $(\mathrm{p}=0.0043)$ lower uptake efficiency difference was found for the $20 \mu \mathrm{M}$ PEG-ma-Ale formulation compared to the $10 \mu \mathrm{M}$ one in 4T1 cells (Fig. 5a), which may be related to the higher surface PEG density. An increase of the incubation time to $24 \mathrm{~h}$ resulted in a 3- to 6-fold increase in particle internalization in $4 \mathrm{~T} 1$ and $\mathrm{J} 774.2$ cells, respectively (Fig. 5b and 5c). In order to investigate whether particles sedimentation could affect CaP NPs cellular internalization, the same experiments were performed for the $24 \mathrm{~h}$ incubation time point with cells in the inverted configuration [42]. As expected, uptake efficiency of CaP NPs was significantly reduced in both cell lines in the inverted set up (cells on top), indicating that the internalization is dependent on the extent of particle sedimentation (Fig. 5b and 5c). We previously reported that the cellular uptake of CaP NPs in different cell lines was strongly influenced by their size, shape and surface PEG density [16,21]. Amorphous spherical particles of 250-280 nm were internalized by HepG2 cells at an almost 4-fold higher 
extent compared to similar NPs of $150 \mathrm{~nm}$ after $4 \mathrm{~h}$ incubation, possibly in part due to a larger sedimentation effect [21]. In addition, a higher surface PEG density generally reduces particles adhesion to cell and hinders their uptake [43]. For example, we reported that the uptake of 80 nm-CaP NPs stabilized with 30 or $40 \mu \mathrm{M}$ PEGylated chelator was drastically decreased to around 10\% compared to larger particles stabilized with a lower PEG concentration [21].

\subsection{Transfection efficiency of CaP NPs in $4 \mathrm{~T} 1$ and J774.2 cells}

The transfection ability of PEG-ma-Ale stabilized CaP NPs loaded with pEGFP plasmid was investigated by flow cytometry in 4T1 and J774.2 cell. CaP NPs were diluted in Opti-MEM supplemented with $10 \%$ FBS and exposed to cells for different incubation times $(5,24$ and 48 h). X-tremeGENETM was used as positive control. The EGFP expression in 4T1 cells increased with incubation time, ranging from a negligible $(<10 \%)$ transfection efficiency after $5 \mathrm{~h}$ cell exposure to CaP NPs, to about 50\% EGFP positive cells after $48 \mathrm{~h}$ incubation, compared to $\sim 80 \%$ cells transfected with xTREMEgene ${ }^{\mathrm{TM}}$ (Fig. 6a and S18). This finding may correlate with a higher amount of CaP NPs internalized by cells for longer incubation times due to a sedimentation effect, as previously discussed. A lower transfection efficiency was observed for the particles coated with $20 \mu \mathrm{M}$ of PEG-ma-Ale compared to $10 \mu \mathrm{M}$, which may be associated to the lower cellular uptake [21]. On the other hand, low or no transfection was observed for J774.2 macrophages incubated with PEG-ma-Ale stabilized CaP NPs (Fig. 6b). In both cell lines, few EGFP expressing cell were detected after $48 \mathrm{~h}$ incubation with the control uncoated CaP precipitates (Fig. S19). Discrepancies in the transfection efficiency of CaP NPs in different cell types were previously highlighted by Neuhaus et al. [44], investigating triple-shell CaP NPs (CaP-DNA-CaP- polyethylenimine). Despite the fact that multi-shell CaP NPs were rapidly taken up by all the cell lines used in their study, a lower transfection efficiency was achieved in 4T1 cells compared to HeLa cells, and no EGFP expressing cells were observed among 
monocytic cell lines. After CaP NPs internalization, endosomal escape of the cargo and DNA processing follow various intracellular mechanisms dependent on the cell type, which may eventually result in a different amount of protein expressed. A high transfection efficiency generally occurs in cells with a high proliferation rate, e.g., Hela, compared to cells that divide slower, such as 4T1 cells [45]. Moreover, due to their scavenging role monocytes and macrophages possess a high enzymatic activity which may result in DNA degradation before the genetic material reaches the nucleus [46]. We previously reported that CaP NPs stabilized with similar PEGylated chelators had a high transfection efficiency in HeLa cells ( $\sim 60 \%$ cells expressing GFP) [16]. The ability of our CaP NPs to transfect 4T1 cells was slightly lower compared to HeLa. On the contrary, their transfection efficiency in macrophages remained low.

\subsection{Cytotoxicity}

The cytotoxicity of PEG-ma-Ale stabilized CaP NPs was evaluated on 4T1 and J774.2 cells, following exposure to the particles for increased PEG-ma-Ale concentrations $(0.5,1,2,4$ and $5 \mu \mathrm{M}$, based on the corresponding Ale molar concentrations) and incubation times $(5,24$ and 48 h). As a control, CaP NPs coated with the non-cleavable PEG-a-Ale derivative were used. These particles had physicochemical properties comparable to those of PEG-ma-Ale stabilized CaP NPs (Table S1), and their characteristics were previously reported [20]. On J774.2 macrophages, PEG-ma-Ale coated CaP NPs induced a time- and concentrationdependent cytotoxic effect, displaying a significant decrease of cell viability ( $60-70 \%)$ after $24 \mathrm{~h}$ exposure to concentrations of conjugated Ale $\geq 0.5 \mu \mathrm{M}$ (Fig. 7a). After $48 \mathrm{~h}$ incubation and PEG-ma-Ale concentrations $\geq 1 \mu \mathrm{M}$, J774.2 viability dropped to less than $20 \%$. Incubation with free PEG-ma-Ale resulted in a moderate but significant decrease of cell viability $(\sim 20-$ $35 \%)$ at high conjugate concentrations $(\geq 4 \mu \mathrm{M})$ (Fig. S20). Conversely, CaP NPs stabilized with the non-cleavable PEG-a-Ale derivative did not display cytotoxicity on macrophages 
under similar conditions (Fig. 7b). Uncoated CaP precipitates (no Ale) had no effect on macrophages viability at the same dilution factor tested for the other CaP NPs formulations (Fig. S21). As shown in Fig. 7c, PEG-ma-Ale associated with CaP NPs was substantially less cytotoxic towards $4 \mathrm{~T} 1$ cells compared to macrophages. Treatment with nitrogen-containing BPs was reported to affect in vitro viability of different cell lines, primarily osteoclasts, monocytes and macrophages. For free Ale, a dose-dependent cytotoxic effect in monocytic and cancer cell lines was observed for rather high concentrations $(20-500 \mu \mathrm{M}$, depending on the cell line) [47-50]. However, adsorption or encapsulation of the BP in nanoparticulate systems were shown to drastically decrease the half maximal inhibitory concentration of Ale, as they facilitated the cellular uptake of the drug [50-53]. BPs induction of apoptosis is correlated to inhibition of the mevalonate pathway, which leads to reduced biosynthesis of isoprenoid compounds that are essential for protein prenylation [49]. Prenylated GTPases, such as Rap, Rho, Rac, Rab and Ras, are involved in the regulation of cytoskeletal organization, cell morphology, endocytosis and apoptosis. Therefore, insufficient GTPases prenylation results in impaired cell function and cell death. To further examine whether cytotoxicity of CaP NPs was mediated by inhibition of FPPS activity, we measured the level of an unprenylated GTPase, Rap1A, after 24 h incubation with CaP NPs coated with PEG-ma-Ale or the more stable control PEG-a-Ale [20]. Accumulation of unprenylated Rap1A was observed in both cell lines treated with CaP NPs bearing the $\mathrm{pH}$-sensitive derivative, at concentrations of conjugated Ale $\geq 0.5$ $\mu \mathrm{M}$ (Fig. 7d and 7e). The effect was stronger on macrophages, for which the particles uptake was slightly higher compared to 4T1 cells (Fig. 5b and 5c). On the other hand, the unprenylated protein was not detected in lysates from cells exposed to PEG-a-Ale chelated CaP NPs. These findings indicate that the cytotoxicity associated to PEG-ma-Ale stabilized CaP NPs in both cell lines was correlated to the inhibition of protein prenylation, which is the major mechanism induced by Ale that ultimately triggers cell apoptosis. Since the protonated form of the Ale nitrogen is required for the binding to FPPS [54], we can hypothesized that $\mathrm{pH}$-driven 
hydrolysis of PEG-ma-Ale allows for a greater intracellular release of Ale. In comparison, no detectable accumulation of unprenylated Rap1A after exposure to PEG-a-Ale stabilized CaP NPs may indicate insufficient cleavage of Ale from the stable conjugate [20].

\subsection{In vivo transfection efficiency}

Since PEG-ma-Ale stabilized CaP NPs displayed good in vitro transfection efficiency in 4T1 cancer cells, we investigated their ability to deliver in vivo pEGFP to xenografted 4T1 breast cancer tumours, following intratumoral injection, to maximize the amount of pDNA delivered to the tumour. Due to hyperosmolality of the reconstituted CaP NPs after concentration, a small volume of CaP NPs formulation $(20 \mu \mathrm{L})$ was slowly injected in multiple spots of the tumor, to avoid pain and tissue damage $[28,55]$. The transfection efficiency study was performed by administration of three single doses of pEGFP loaded CaP NPs (each dose consisting of $2 \mu \mathrm{g}$ ), every other day over one week. In vivo-jetPEI ${ }^{\circledR}$, a commercial cationic polymer-based agent for in vivo transfection, was used as a positive control. A low GFP expression was found in the tumors injected with PEG-ma-Ale stabilized CaP NPs, which was similar to that of in vivojetPEI $^{\circledR}$. On the other hand, a lower transfection was observed after administration of the naked plasmid, suggesting that pDNA incorporation in NPs increases the degree of DNA transfer efficiency across the cell membrane. However, the low in vivo transfection efficacy of the PEGma-Ale coated CaP NPs could be potentially explained by a lower pDNA dose compared to those found in the literature [56], a lower particle uptake in vivo (due to the absence of a sedimentation effect) and/or to the premature $\mathrm{CaP}$ dissolution (and subsequent extracellular pDNA release) that may occur under dilute conditions [57]. Moreover, particles aggregation at the injection site and/or poor diffusion through the extracellular matrix could also have impaired the transfection ability of the system. 


\section{Conclusions}

In the present study, an acid-cleavable PEG-Ale conjugate was used to generate stable CaP NPs loaded with pEGFP and allow the combined cellular uptake of the two poorly permeable compounds. In vitro, the $\mathrm{pH}$ responsive nanocarrier exhibited good transfection efficiency in cancer cells and a strong cytotoxic effect on macrophages with potent inhibition of the mevalonate pathway, probably due to efficient endo/lysosomal cleavage of the BP from the particle coating. By providing an efficient approach for the combined delivery of drugs, further anticancer applications may be envisaged, i.e. replacing the model pDNA with therapeutic nucleic acids, if the in vivo transfection efficiency is improved. The introduction of a selected targeting ligand on the particles surface could boost their uptake in cancer cells or tumour associated macrophages, overcoming the negative effect of the PEG layer on internalization. While particle dissolution under mildly acidic condition allows for the complete discharge of the payload, further optimization strategies are needed to improve the stability of CaP NPs, which tend to dissolve under highly diluted conditions, such as those encountered in vivo. For example, particle dissolution may be tuned varying the crystalline phase of the nanomaterial [58], investigating hydrothermal treatments or synthetic routes that allow for a precise control over the $\mathrm{Ca} / \mathrm{P}$ ratio [59].

\section{Acknowledgments}

The authors wish to thank Catherine Cailleau at Institut Galien Paris-Sud, UMR8612, Université Paris-Sud, for the technical assistance in animal experiments. The Scientific Center for Optical and Electron Microscopy (ScopeM) of ETH Zurich is gratefully acknowledged for use of the facility, and especially Dr. Fabian Gramm for TEM and SAED analyses and Dr. Gabriella Éva Bodizs and Joachim Hehl for assistance with the cryostat and with EGFP staining. Antonia Schantl is acknowledged for proofreading of the manuscript. This work was 
financially supported by the State Secretariat for Education, Research and Innovation (SERI) in the context of the European Union's HORIZON 2020 Programme (Marie Curie ITN European NABBA project, no. 642028) and a Natural Sciences and Engineering Research Council of Canada Discovery Grant (RGPIN-2015-05364). The authors declare no conflict of interest.

\section{Bibliography}

[1] D. Ibraheem, A. Elaissari, H. Fessi, Gene therapy and DNA delivery systems, Int. J. Pharm., 459 (2014), 70-83.

[2] K. Kawabata, Y. Takakura, M. Hashida, The fate of plasmid DNA after intravenous injection in mice: involvement of scavenger receptors in its hepatic uptake, Pharm. Res., 12 (1995), 825-830.

[3] H. Tian, J. Chen, X. Chen, Nanoparticles for gene delivery, Small, 9 (2013), 2034-2044.

[4] Y. Xiao, K. Shi, Y. Qu, B. Chu, Z. Qian, Engineering nanoparticles for targeted delivery of nucleic acid therapeutics in tumor, Mol. Ther. - Methods Clin. Dev., 12 (2019), 1-18.

[5] J. Panyam, V. Labhasetwar, Biodegradable nanoparticles for drug and gene delivery to cells and tissue, Adv. Drug Deliv. Rev., 55 (2003), 329-347.

[6] H. Cohen, R.J. Levy, J. Gao, I. Fishbein, V. Kousaev, S. Sosnowski, S. Slomkowski, G. Golomb, Sustained delivery and expression of DNA encapsulated in polymeric nanoparticles, Gene Ther., 7 (2000), 1896-1905.

[7] C. Qiu, W. Wei, J. Sun, H.-T. Zhang, J.-S. Ding, J.-C. Wang, Q. Zhang, Systemic delivery of siRNA by hyaluronan-functionalized calcium phosphate nanoparticles for tumor-targeted therapy, Nanoscale, 8 (2016), 13033-13044. 
[8] C. Tros de Ilarduya, Y. Sun, N. Düzgüneş, Gene delivery by lipoplexes and polyplexes, Eur. J. Pharm. Sci., 40 (2010), 159-170.

[9] J.-S. Zhang, F. Liu, L. Huang, Implications of pharmacokinetic behavior of lipoplex for its inflammatory toxicity, Adv. Drug Deliv. Rev., 57 (2005), 689-698.

[10] K. Kataoka, A. Harada, Y. Nagasaki, Block copolymer micelles for drug delivery: design, characterization and biological significance, Adv. Drug Deliv. Rev., 47 (2001), $113-131$.

[11] A. Pensado, B. Seijo, A. Sanchez, Current strategies for DNA therapy based on lipid nanocarriers, Expert Opin. Drug Deliv., 11 (2014), 1721-1731.

[12] J. Chen, Z. Guo, H. Tian, X. Chen, Production and clinical development of nanoparticles for gene delivery, Mol. Ther. - Methods Clin. Dev., 3 (2016), 16023.

[13] M.K. Riley, W. Vermerris, W. Vermerris, Recent advances in nanomaterials for gene delivery - a review, Nanomater. (Basel, Switzerland), 7 (2017), 94.

[14] A. Maitra, Calcium phosphate nanoparticles: second-generation nonviral vectors in gene therapy, Expert Rev. Mol. Diagn., 5 (2005), 893-905.

[15] P. Batard, M. Jordan, F. Wurm, Transfer of high copy number plasmid into mammalian cells by calcium phosphate transfection, Gene, 270 (2001), 61-68.

[16] E. V. Giger, J. Puigmartí-Luis, R. Schlatter, B. Castagner, P.S. Dittrich, J.-C. Leroux, Gene delivery with bisphosphonate-stabilized calcium phosphate nanoparticles, J. Control. Release, 150 (2011), 87-93.

[17] Y. Kakizawa, S. Furukawa, A. Ishii, K. Kataoka, Organic-inorganic hybrid-nanocarrier of siRNA constructing through the self-assembly of calcium phosphate and PEG-based 
block aniomer, J. Control. Release, 111 (2006), 368-370.

[18] J. Li, Y. Yang, L. Huang, Calcium phosphate nanoparticles with an asymmetric lipid bilayer coating for siRNA delivery to the tumor, J. Control. Release, 158 (2012), 108114.

[19] V. Sokolova, A. Kovtun, O. Prymak, W. Meyer-Zaika, E.A. Kubareva, E.A. Romanova, T.S. Oretskaya, R. Heumann, M. Epple, Functionalisation of calcium phosphate nanoparticles by oligonucleotides and their application for gene silencing, J. Mater. Chem., 17 (2007), 721-727.

[20] E. V. Giger, B. Castagner, J. Räikkönen, J. Mönkkönen, J.-C. Leroux, siRNA transfection with calcium phosphate nanoparticles stabilized with PEGylated chelators, Adv. Healthc. Mater., 2 (2013), 134-144.

[21] X. Huang, D. Andina, J. Ge, A. Labarre, J.-C. Leroux, B. Castagner, characterization of calcium phosphate nanoparticles based on a PEGylated chelator for gene delivery, ACS Appl. Mater. Interfaces, 9 (2017), 10435-10445.

[22] M. Salerno, E. Cenni, C. Fotia, S. Avnet, D. Granchi, F. Castelli, D. Micieli, R. Pignatello, M. Capulli, N. Rucci, A. Angelucci, A. Del Fattore, A. Teti, N. Zini, A. Giunti, N. Baldini, Bone-targeted doxorubicin-loaded nanoparticles as a tool for the treatment of skeletal metastases, Curr. Cancer Drug Targets, 10 (2010), 649-659.

[23] E. V. Giger, B. Castagner, J.-C. Leroux, Biomedical applications of bisphosphonates, J. Control. Release, 167 (2013), 175-188.

[24] V. Stresing, F. Daubiné, I. Benzaid, H. Mönkkönen, P. Clézardin, Bisphosphonates in cancer therapy, Cancer Lett., 257 (2007), 16-35. 
[25] P. Clézardin, Mechanisms of action of bisphosphonates in oncology: a scientific concept evolving from antiresorptive to anticancer activities, Bonekey Rep., 2 (2013), 267.

[26] P. Clézardin, Bisphosphonates' antitumor activity: an unravelled side of a multifaceted drug class, Bone, 48 (2011), 71-79.

[27] M. Rogers, New insights into the molecular mechanisms of action of bisphosphonates, Curr. Pharm. Des., 9 (2003), 2643-2658.

[28] W. Wang, Tolerability of hypertonic injectables, Int. J. Pharm., 490 (2015), 308-315.

[29] J.L. Wike-Hooley, J. Haveman, H.S. Reinhold, The relevance of tumour pH to the treatment of malignant disease, Radiother. Oncol., 2 (1984), 343-366.

[30] W.A. Blattler, B.S. Kuenzi, J.M. Lambert, P.D. Senter, New heterobifunctional protein crosslinking reagent that forms an acid-labile link, Biochemistry, 24 (1985), 1517-1524.

[31] H. Kamada, Y. Tsutsumi, Y. Yoshioka, Y. Yamamoto, H. Kodaira, S. Tsunoda, T. Okamoto, Y. Mukai, H. Shibata, S. Nakagawa, T. Mayumi, Design of a pH-Sensitive Polymeric Carrier for Drug Release and Its Application in Cancer Therapy, Clin. Cancer Res., 10 (2004), 2545-2550.

[32] D.B. Rozema, K. Ekena, D.L. Lewis, A.G. Loomis, J.A. Wolff, Endosomolysis by masking of a membrane-active agent (EMMA) for cytoplasmic release of macromolecules, Bioconjug Chem., 14 (2003), 51-57.

[33] M. Meyer, A. Philipp, R. Oskuee, C. Schmidt, E. Wagner, Breathing life into polycations: functionalization with $\mathrm{pH}$-responsive endosomolytic peptides and polyethylene glycol enables siRNA delivery, J. Am. Chem. Soc., 130 (2008), 3272-3273.

[34] M. Meyer, A. Zintchenko, M. Ogris, E. Wagner, A dimethylmaleic acid-melittin- 
polylysine conjugate with reduced toxicity, $\mathrm{pH}$-triggered endosomolytic activity and enhanced gene transfer potential, J. Gene Med., 9 (2007), 797-805.

[35] S. Kang, Y. Kim, Y. Song, J.U. Choi, E. Park, W. Choi, J. Park, Y. Lee, Comparison of pH-sensitive degradability of maleic acid amide derivatives, Bioorg. Med. Chem. Lett. 24 (2014), 2364-2367.

[36] A.J. Kirby, P.W. Lancaster, Structure and efficiency in intramolecular and enzymic catalysis. Catalysis of amide hydrolysis by the carboxy-group of substituted maleamic acids, J. Chem. Soc. Perkin Trans. 2, 0 (1972), 1206-1214.

[37] A.J. Kirby, Effective molarities for intramolecular reactions, Adv. Phys. Org. Chem., 17 (1980), 183-278.

[38] P. Liang, D. Zhao, C.-Q. Wang, J.-Y. Zong, R.-X. Zhuo, S.-X. Cheng, Facile preparation of heparin $/ \mathrm{CaCO}_{3} / \mathrm{CaP}$ hybrid nano-carriers with controllable size for anticancer drug delivery, Colloids Surfaces B Biointerfaces, 102 (2013), 783-788.

[39] F. Ridi, I. Meazzini, B. Castroflorio, M. Bonini, D. Berti, P. Baglioni, Functional calcium phosphate composites in nanomedicine, Adv. Colloid Interface Sci., 244 (2017), 281295.

[40] E. Bertoni, A. Bigi, G. Falini, S. Panzavolta, N. Roveri, Hydroxyapatite/polyacrylic acid nanocrystals, J. Mater. Chem., 9 (1999), 779-782.

[41] W.J.E.M. Habraken, J. Tao, L.J. Brylka, H. Friedrich, L. Bertinetti, A.S. Schenk, A. Verch, V. Dmitrovic, P.H.H. Bomans, P.M. Frederik, J. Laven, P. van der Schoot, B. Aichmayer, G. de With, J.J. DeYoreo, N.A.J.M. Sommerdijk, Ion-association complexes unite classical and non-classical theories for the biomimetic nucleation of calcium phosphate, Nat. Commun., 4 (2013), 1507. 
[42] E.C. Cho, Q. Zhang, Y. Xia, The effect of sedimentation and diffusion on cellular uptake of gold nanoparticles, Nat. Nanotechnol., 6 (2011), 385-391.

[43] C.D. Walkey, J.B. Olsen, H. Guo, A. Emili, W.C.W. Chan, Nanoparticle size and surface chemistry determine serum protein adsorption and macrophage uptake, J. Am. Chem. Soc., 134 (2012), 2139-2147.

[44] B. Neuhaus, B. Tosun, O. Rotan, A. Frede, A.M. Westendorf, M. Epple, Nanoparticles as transfection agents: a comprehensive study with ten different cell lines, RSC Adv., 6 (2016), 18102-18112.

[45] I. Kirchenbuechler, D. Kirchenbuechler, M. Elbaum, Correlation between cationic lipidbased transfection and cell division, Exp. Cell Res., 345 (2016), 1-5.

[46] S. Dokka, D. Toledo, X. Shi, J. Ye, Y. Rojanasakul, High-efficiency gene transfection of macrophages by lipoplexes, Int. J. Pharm., 206 (2000), 97-104.

[47] S. Patntirapong, M. Poolgesorn, Alteration of macrophage viability, differentiation, and function by bisphosphonates, Oral Dis., 24 (2018), 1294-1302.

[48] C. Schem, R.J. Tower, P. Kneissl, A.-C. Rambow, G.M. Campbell, C. Desel, T. Damm, T. Heilmann, S. Fuchs, M. Zuhayra, A. Trauzold, C.C. Glüer, S. Schott, S. Tiwari, Pharmacologically inactive bisphosphonates as an alternative strategy for targeting osteoclasts: in vivo assessment of 5-fluorodeoxyuridine-alendronate in a preclinical model of breast cancer bone metastases, J. Bone Miner. Res., 32 (2017), 536-548.

[49] S.P. Luckman, D.E. Hughes, F.P. Coxon, R.G.G. Russell, M.J. Rogers, Nitrogencontaining bisphosphonates inhibit the mevalonate pathway and prevent posttranslational prenylation of GTP-binding proteins, including Ras, J. Bone Miner. Res., 13 (1998), 581-589. 
[50] F. Benyettou, R. Rezgui, F. Ravaux, T. Jaber, K. Blumer, M. Jouiad, L. Motte, J.-C. Olsen, C. Platas-Iglesias, M. Magzoub, A. Trabolsi, Synthesis of silver nanoparticles for the dual delivery of doxorubicin and alendronate to cancer cells, J. Mater. Chem. B, 3 (2015), 7237-7245.

[51] C.M. Conners, V.R. Bhethanabotla, V.K. Gupta, Concentration-dependent effects of alendronate and pamidronate functionalized gold nanoparticles on osteoclast and osteoblast viability, J. Biomed. Mater. Res. Part B Appl. Biomater., 105 (2017), 21-29.

[52] F. Fanord, K. Fairbairn, H. Kim, A. Garces, V. Bhethanabotla, V.K. Gupta, Bisphosphonate-modified gold nanoparticles: a useful vehicle to study the treatment of osteonecrosis of the femoral head, Nanotechnology, 22 (2011), 35102.

[53] J. Gu, M. Huang, J. Liu, Y. Li, W. Zhao, J. Shi, Calcium doped mesoporous silica nanoparticles as efficient alendronate delivery vehicles, New J. Chem., 36 (2012), 1717.

[54] M.B. Martin, W. Arnold, H.T. Heath, J.A. Urbina, E. Oldfield, Nitrogen-containing bisphosphonates as carbocation transition state analogs for isoprenoid biosynthesis, Biochem. Biophys. Res. Commun., 263 (1999), 754-758.

[55] O. Svendsen, C.N. Edwards, B. Lauritzen, A.D. Rasmussen, Intramuscular injection of hypertonic saline: in vitro and in vivo muscle tissue toxicity and spinal neurone c-fos expression, Basic Clin. Pharmacol. Toxicol., 97 (2005) 52-57.

[56] T. Nomura, S. Nakajima, K. Kawabata, F. Yamashita, Y. Takakura, M. Hashida, Intratumoral pharmacokinetics and in vivo gene expression of naked plasmid DNA and its cationic liposome complexes after direct gene transfer, Cancer Res., 57 (1997), 26812686.

[57] S. Bisso, A. Degrassi, D. Brambilla, J.-C. Leroux, Poly(ethylene glycol)-alendronate 
coated nanoparticles for magnetic resonance imaging of lymph nodes, J. Drug Target., (2019), https://doi.org/10.1080/1061186X.2018.1545235.

[58] M.C. Rodrigues, L.C. Natale, V.E. Arana-Chaves, R.R. Braga, Calcium and phosphate release from resin-based materials containing different calcium orthophosphate nanoparticles, J. Biomed. Mater. Res. Part B Appl. Biomater., 103 (2015), 1670-1678.

[59] M. Sadat-Shojai, M.-T. Khorasani, E. Dinpanah-Khoshdargi, A. Jamshidi, Synthesis methods for nanosized hydroxyapatite with diverse structures, Acta Biomater., 9 (2013), $7591-7621$. 


\section{Graphical abstract}

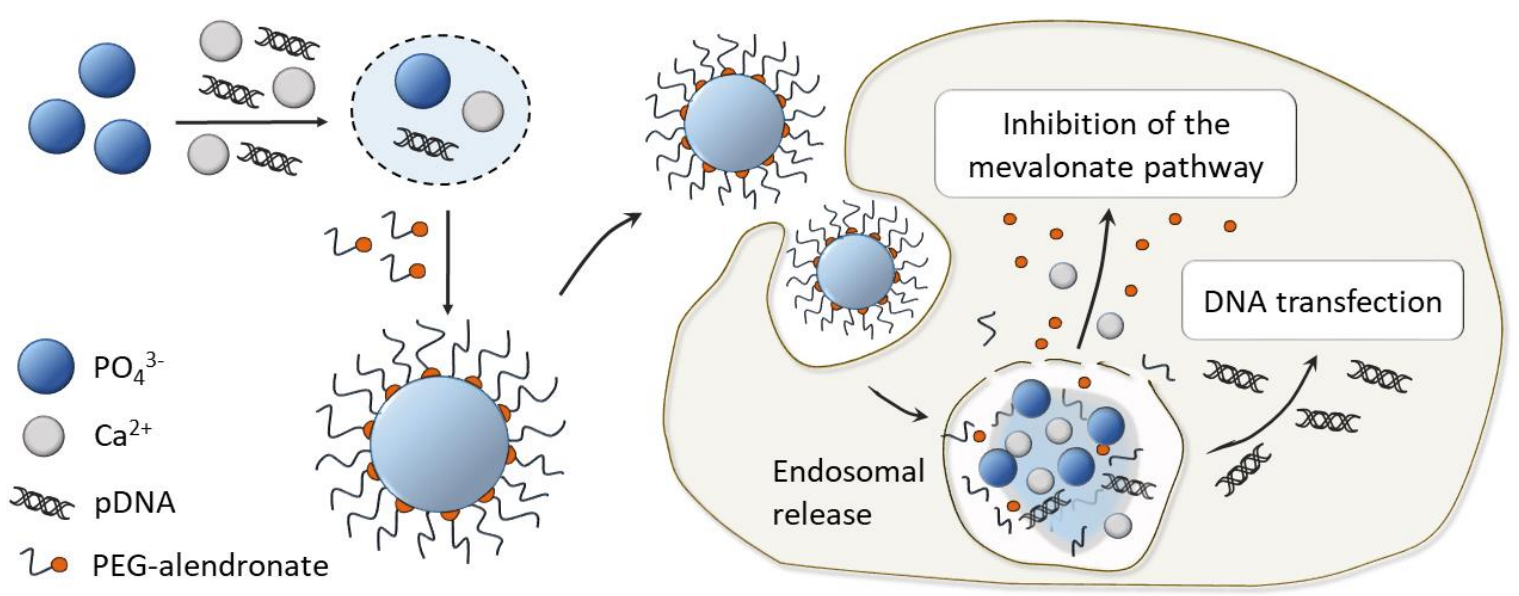

a.

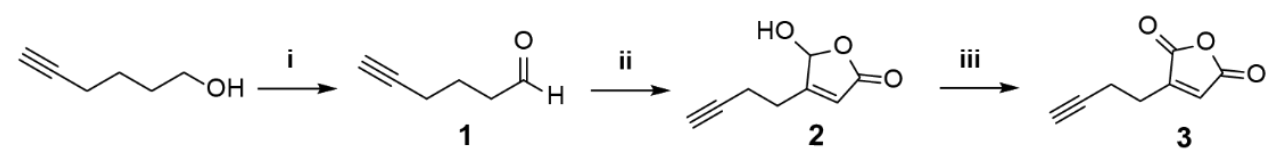

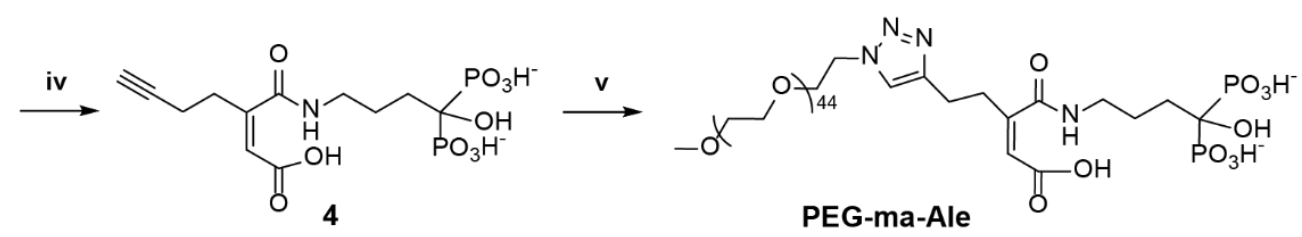

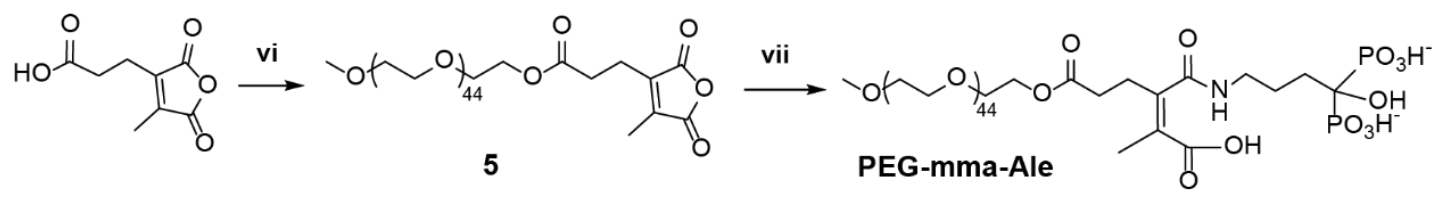

Figure 1. Synthesis of PEG-ma-Ale (a) and PEG-mma-Ale (b). Reagents and conditions: (i) 1. oxalyl chloride, dimethyl sulfoxide, dichloromethane (DCM), $-78^{\circ} \mathrm{C} ; 2$. triethylamine, $-78^{\circ} \mathrm{C}$; (ii) Glyoxylic acid monohydrate, morpholine $\cdot$ hydrochloric acid salt, aq. dioxane, $100{ }^{\circ} \mathrm{C}$, (iii) Dess-Martin periodinane, DCM, RT; (iv) Ale sodium trihydrate, water, pH 9; (v) mPEG-azide, copper(I) bromide, tris((1-benzyl-4-triazolyl)methyl)amine, aq. dimethyl sulfoxide/tertbutanol, pH 8.5; (vi) 1. oxalyl chloride, dimethylformamide, DCM; 2. mPEG-OH, DCM; (vii) Ale sodium trihydrate, water, $\mathrm{pH} 9-10$. 


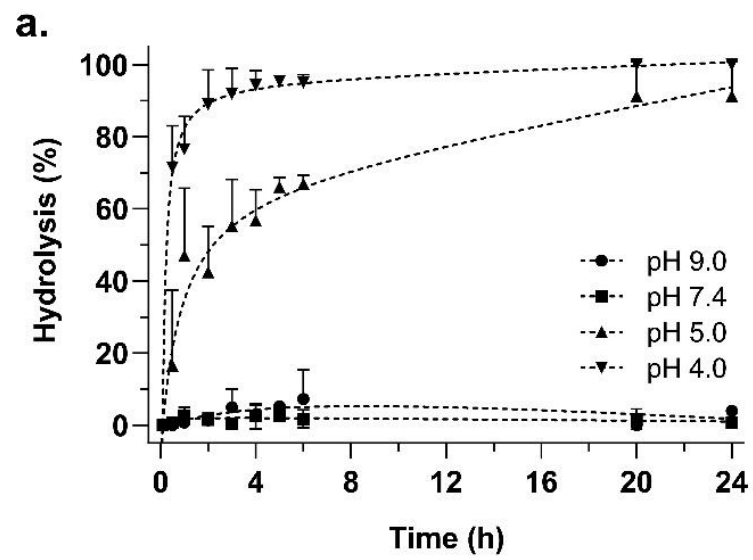

b.

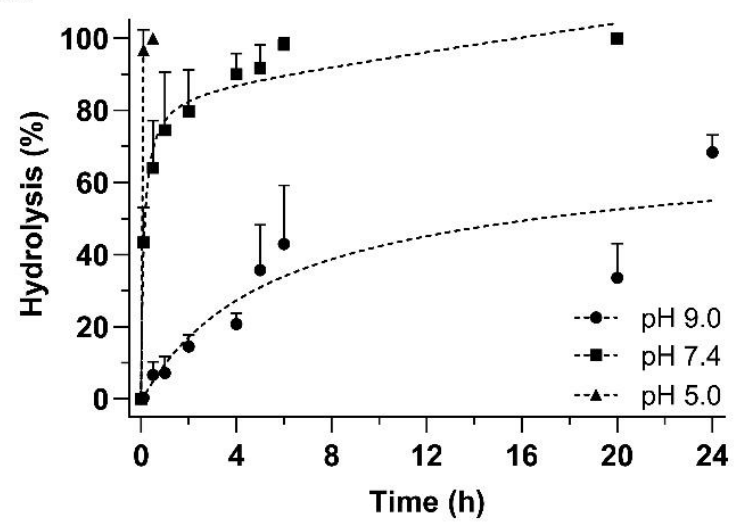

Figure 2. Hydrolysis of PEG-ma-Ale (a) and PEG-mma-Ale (b) cleavable conjugates at different pHs. PEG-ma-Ale showed excellent stability after $24 \mathrm{~h}$ incubation at both $\mathrm{pH} 9.0$ and 7.4 ( $<10 \%$ hydrolysis). A sustained Ale release was observed at $\mathrm{pH} 5.0$, with $\sim 50 \%$ hydrolysis reached after about $3 \mathrm{~h}$. At $\mathrm{pH} 4.0$, the conjugate was almost completely cleaved (> 80\%) within $1 \mathrm{~h}$. On the other hand, PEG-mma-Ale showed rapid cleavage at $\mathrm{pH} 7.4$ and 5.0 and slow amide cleavage at $\mathrm{pH}$ 9.0. Data are presented as mean $+\mathrm{SD}(\mathrm{n}=3)$. 
a.

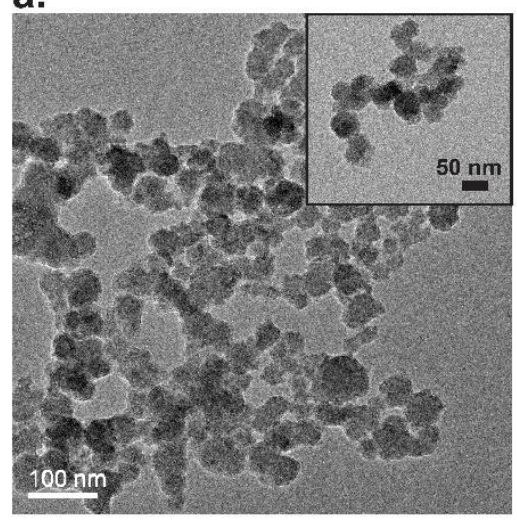

b.

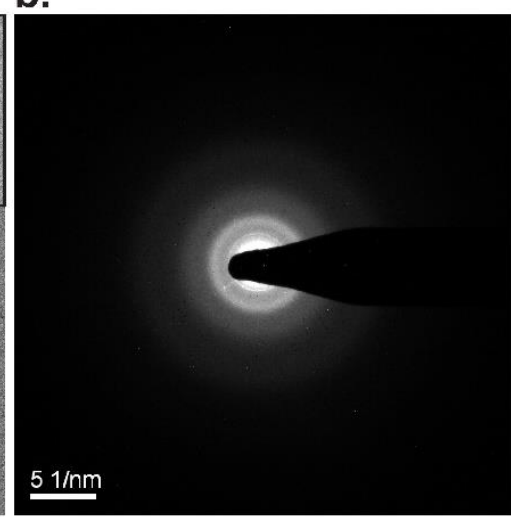

Figure 3. CaP precipitates formed spherical amorphous NPs. TEM micrograph (a) and SAED acquisition (b) of CaP NPs prepared with $10 \mu \mathrm{M}$ PEG-ma-Ale.

a.

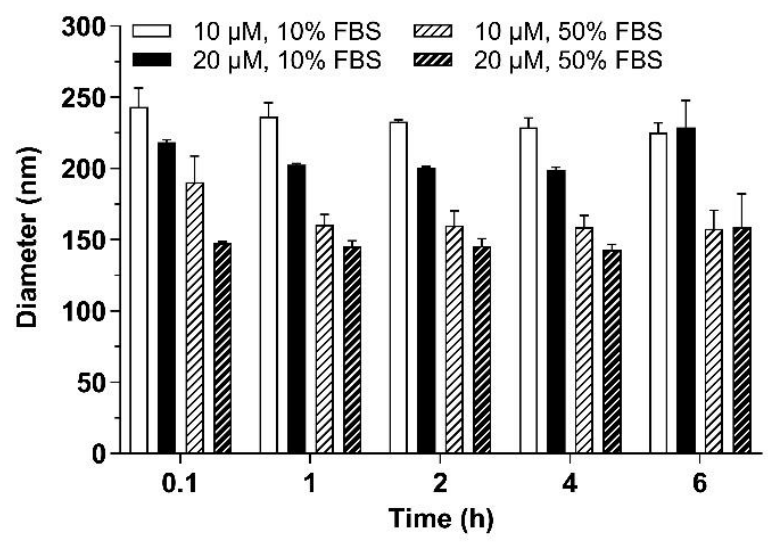

b.

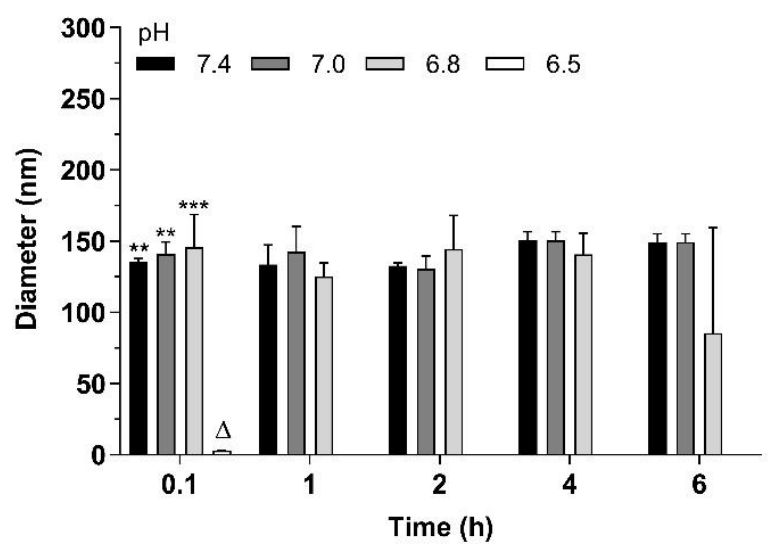

Figure 4. PEG-ma-Ale-chelated CaP NPs were stable in FBS-containing media, and quickly dissolved at mild acidic pH. The hydrodynamic diameter of PEGylated CaP NPs (PEG-ma-Ale $10 \mu \mathrm{M}$ or $20 \mu \mathrm{M}$ ) was measured by DLS in the presence of 10 or $50 \%$ FBS (a). Size of CaP NPs was constant between $\mathrm{pH} 7.8$ and 6.8, and the particles almost completely dissolved $(\Delta)$ upon acidification to $\mathrm{pH} 6.5$ (b). Data are expressed as mean $+\mathrm{SD}(\mathrm{n}=3)$. ** $\mathrm{p} \leq 0.01$ and $* * *$ $\mathrm{p} \leq 0.001$ vs. $\mathrm{pH} 6.5,0.1 \mathrm{~h}$. 
a.

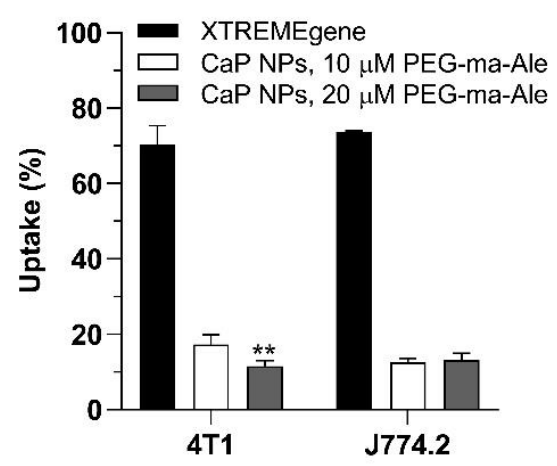

b.

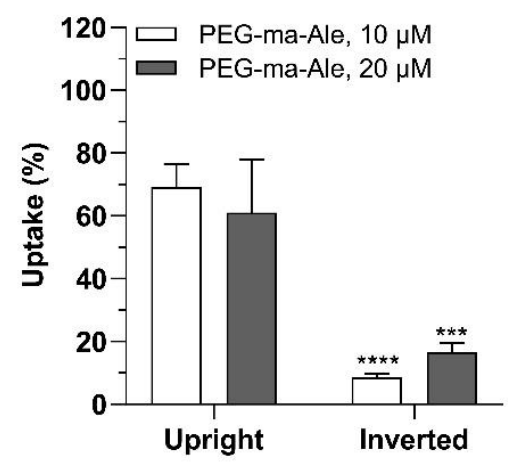

c.

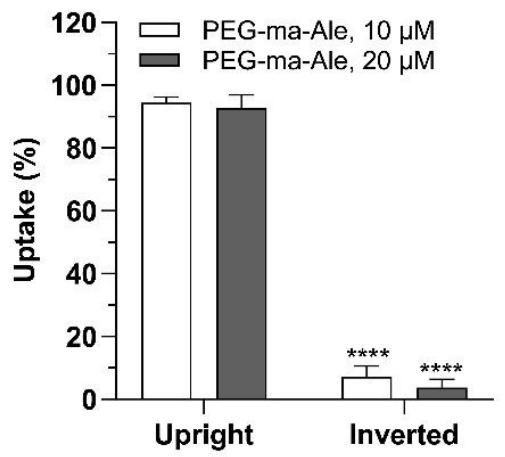

Figure 5. Cellular uptake of PEG-ma-Ale stabilized CaP NPs encapsulating a fluorescently labelled pDNA, after $5 \mathrm{~h}$ incubation with $4 \mathrm{~T} 1$ and J774.2 cells (a), and after $24 \mathrm{~h}$ incubation in upright or inverted set-up with 4T1 (b) and J774.2 (c) cells. A 0.5- $\mu$ g amount of DNA per well was applied and X-tremGENETM ${ }^{\text {was }}$ used as positive control. Data are expressed as mean + $\mathrm{SD}, \mathrm{n}=3-6 . * * \mathrm{p} \leq 0.01 v s . \mathrm{CaP}$ NPs, $10 \mu \mathrm{M}$ PEG-ma-Ale on $4 \mathrm{~T} 1$ cells; $* * * \mathrm{p} \leq 0.001$ and $* * * *$ $\mathrm{p} \leq 0.0001$ vs. CaP NPs in the upright configuration at the same PEG-ma-Ale concentration.
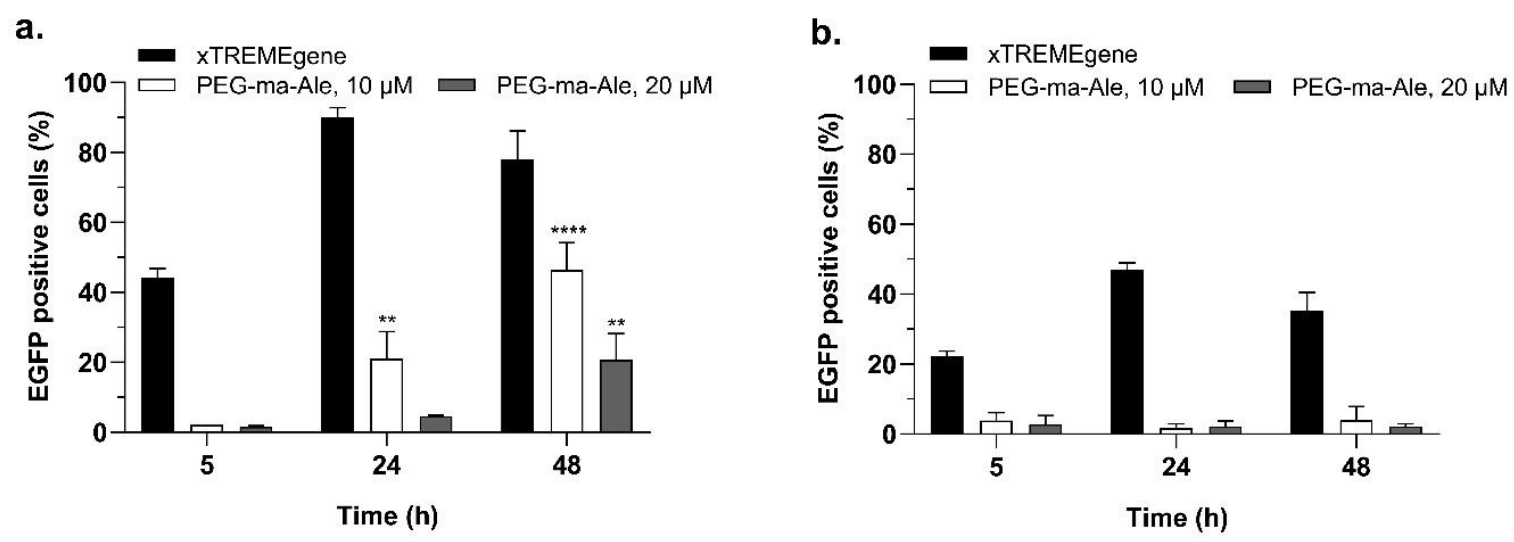

Figure 6. Influence of incubation time and PEG-ma-Ale concentration on transfection efficiency of CaP NPs in 4T1 (a) and J774.2 (b) cells in Opti-MEM containing 10\% FBS. A prolongation of the incubation time from 5 to $48 \mathrm{~h}$ significantly increased the percentage of EGFP positive cells among 4T1 cells. In contrast, low CaP NPs transfection efficiency was observed in J774.2 cells at all tested conditions. Results are expressed as mean + SD (n=3-6). ** $\mathrm{p} \leq 0.01$ and $* * * \mathrm{p} \leq 0.0001$ vs. $5 \mathrm{~h}$ incubation with CaP NPs at the same PEG-ma-Ale 
feeding concentration.
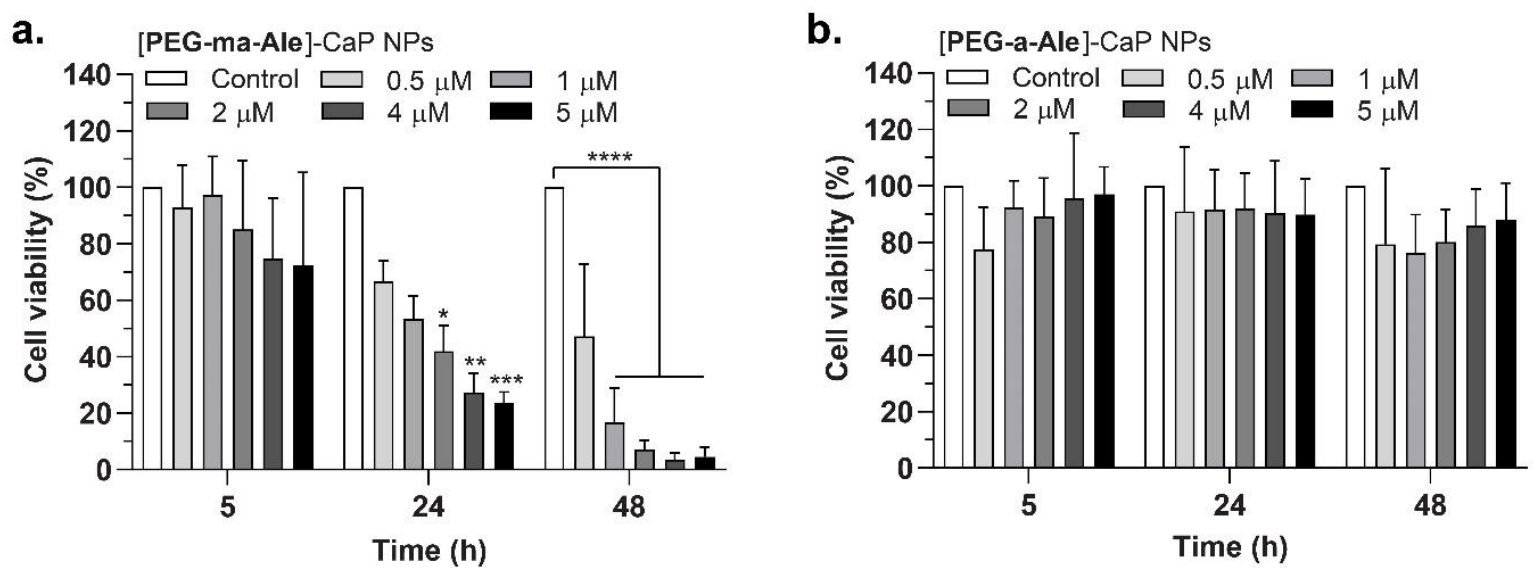

C.

d.
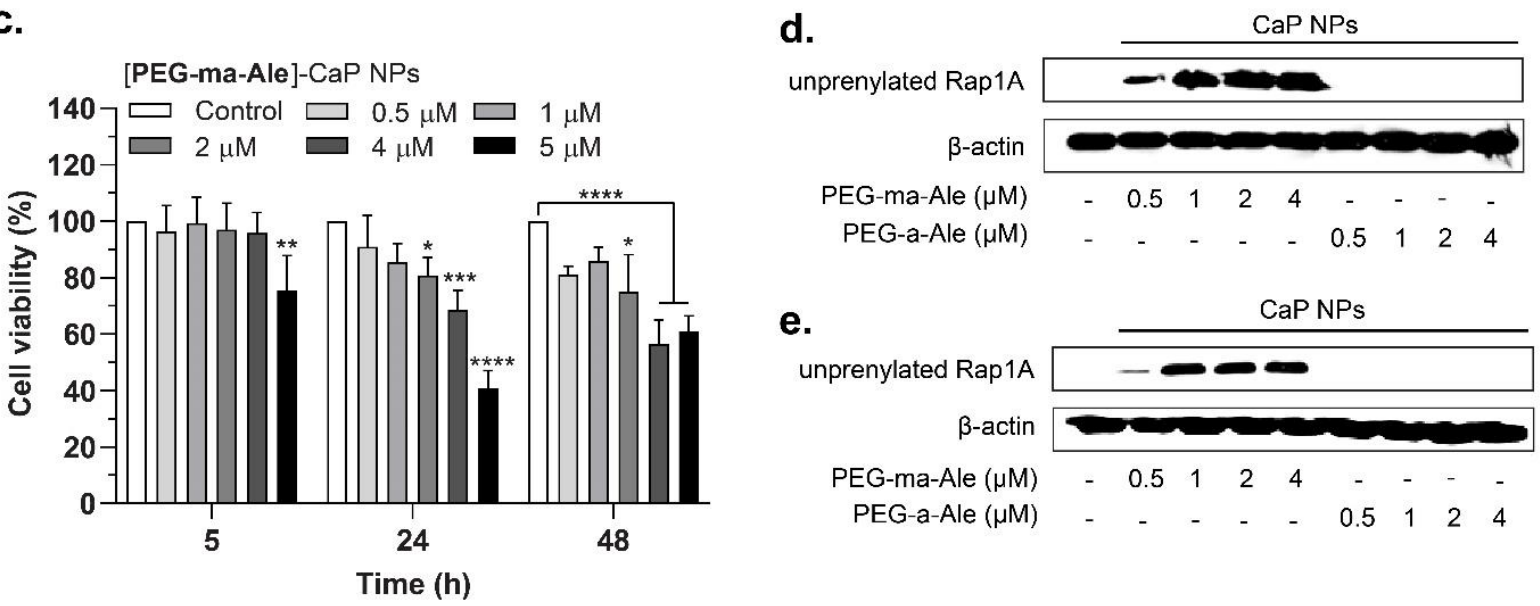

Figure 7. PEG-ma-Ale stabilized CaP NPs affected cell viability of macrophages and cancer cells and induced accumulation of unprenylated Rap1A, via inhibition of the mevalonate pathway. Cell viability after 5, 24 or $48 \mathrm{~h}$ incubation of PEG-ma-Ale stabilized CaP NPs (a) and PEG-a-Ale stabilized CaP NPs (b) with J774.2 cells. In the same way, 4T1 cell viability was evaluated after exposure to PEG-ma-Ale coated CaP NPs (c). Data are expressed as mean $+\mathrm{SD}$ of three independent experiments performed in triplicate. ${ }^{*} \mathrm{p} \leq 0.05 ; * * \mathrm{p} \leq 0.01 ; * * * \mathrm{p}$ $\leq 0.001 ; * * * * \mathrm{p} \leq 0.001 v s$. control wells (not treated). Western blot analyses were performed to examine unprenylated Rap1A accumulation in J774.2 (d) and 4T1 (e) cell lysates after $24 \mathrm{~h}$ incubation with CaP NPs coated with PEG-ma-Ale or PEG-a-Ale. Representative Western blot of 3 independent experiments. 


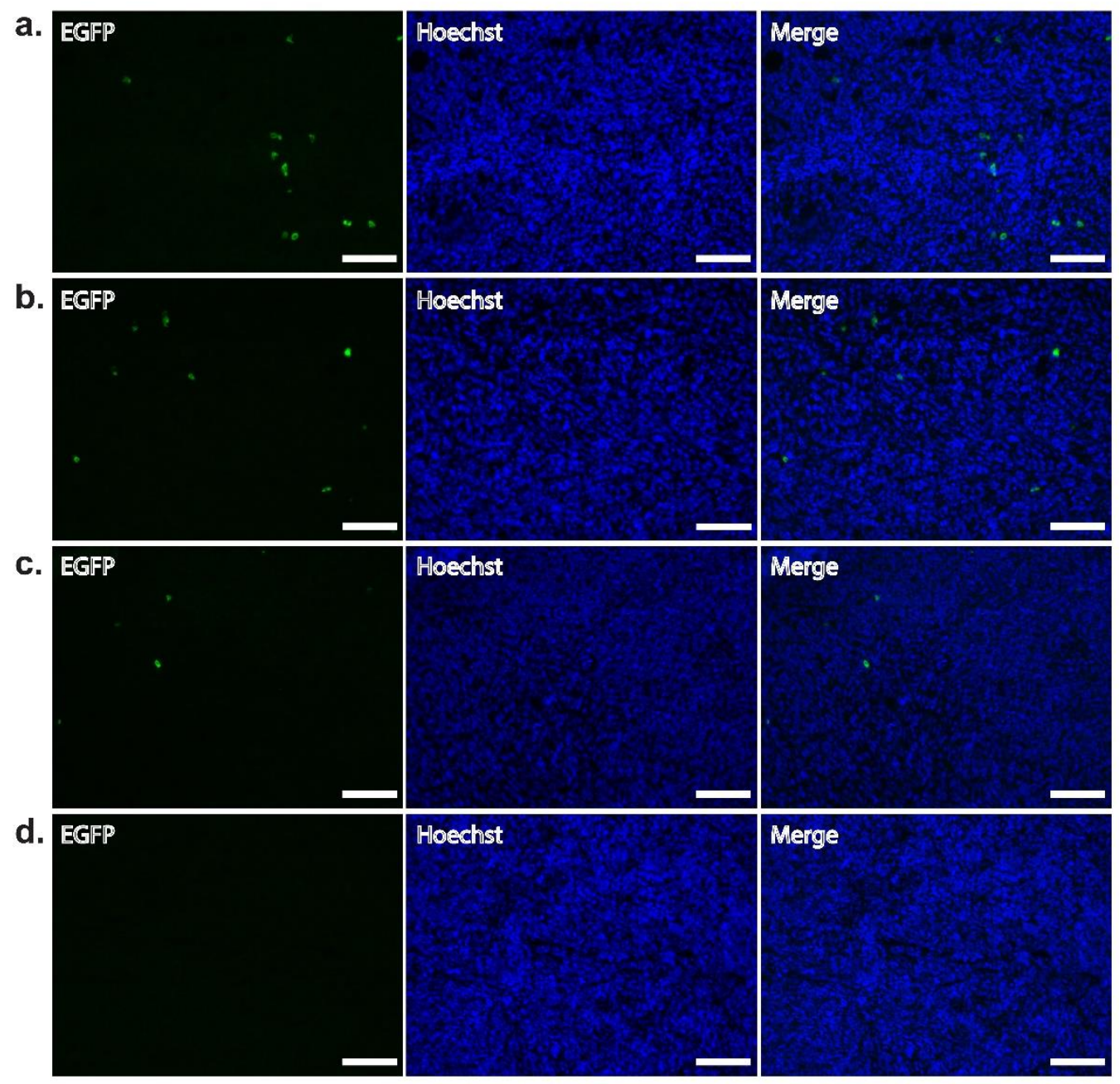

Figure 8. Representative fluorescence micrographs of histological analysis of tumour frozen sections after administration of PEG-ma-Ale stabilized CaP NPs (a) in vivo-jetPEI ${ }^{\circledR}$ (b) and naked pEGFP (c). A solution of $5 \%(\mathrm{~m} / \mathrm{v})$ glucose was used as negative control (d). The formulations were injected intratumorally in 4T1 xenografts in BALC/c mice every other day for one week. Samples were isolated $24 \mathrm{~h}$ after the last injection. For EGFP visualization, the tissue slices were stained with ATTO488-GFP Booster. Scale bar represents $100 \mu \mathrm{m}$. 
Table 1. Physicochemical properties of PEG-ma-Ale coated CaP NPs. Means \pm SD $(n=3-6)$.

Blank CaP NPs

\begin{tabular}{|c|c|c|c|c|}
\hline PEG-ma-Ale $(\mu \mathrm{M})$ & 10 & 20 & 10 & 20 \\
\hline Diameter (nm) & $138 \pm 7$ & $142 \pm 4$ & $170 \pm 8$ & $162 \pm 4$ \\
\hline PDI & 0.19 & 0.14 & 0.105 & 0.115 \\
\hline$\zeta$-potential & $-5 \pm 1$ & $-1 \pm 3$ & $-3 \pm 2$ & $-3 \pm 2$ \\
\hline
\end{tabular}

